\title{
Optimal audit policies with heterogeneous agents
}

\author{
Fernando García Alvarado ${ }^{a, b}$ \\ ${ }^{a}$ Department of Economics - Università Ca' Foscari Venezia \\ ${ }^{b}$ Centre d'Économie de la Sorbonne - Université Paris 1 Panthéon-Sorbonne
}

\begin{abstract}
This paper considers a tax evasion game where the tax authority intends to prevent income under-reporting within a network of heterogeneous taxpayers who are engaged in social interactions and exchange information. I propose a two-step game-theoretic optimal audit strategy from the point of view of the tax authority, which consists of a credible threat-to-audit message followed by a network-based audit policy. Subsequently, the tax authority targets taxpayers in function of their individual productivity and their position inside the network, triggering a series of spillover effects which eventually maximize the mean perceived subjective probability of being audited among all taxpayers. Moreover, the optimal audit strategy is robust to expected and non-expected utility theories, and it is invariant for any taxpayer utility function. Additionally, computer simulations determined that the proposed enforcement regime is robust to an ample range of parameter specifications and settings.
\end{abstract}

JEL classification: H26 - D85 - C54

Keywords: Tax Evasion · Networks · Quantitative Policy

\section{Introduction}

Income under-reporting depletes tax collection and fiscal revenues for tax authorities. According to Buehn and Schneider (2012) the average size of tax evasion originating from under-reported income and indirect taxes amounted to $3.2 \%$ of the GDP among OECD countries over the period 1999 to 2010. Likewise, Kukk, Paulus, and Staehr (2020) estimated that between $10 \%$ and $40 \%$ of self-employed income declarations are under-reported by individuals across EU countries. Gamannossi degl'Innocenti and Rablen (2020) claimed that income tax evasion forces developed countries to annually forsake up to $20 \%$ of the taxes which otherwise should have been collected. Moreover, Scartascini and Castro (2015) concluded that the problem is even more pronounced for developing countries, which are sometimes able to only secure less than half of their planned tax collections.

As stated in Kirchler, Hoelzl, and Wahl (2008) income tax compliance may be enforced by the tax authority (also referred to as social planner) or it may originate from voluntary motives appertaining to taxpayers (also referred to as agents or individuals). Following, tax compliance is influenced not only by enforcement and penalty levels, but also by the applicable tax rates, the appropriate use of public money by the government, feelings of regret, uncertainty, risk aversion, psychic costs of evading, the behavior of fellow taxpayers, peer effects, social interactions, reciprocity, social norms, the efficiency of government expenditures, tax morale and the degree of trust that citizens place in the authority; to mention a few. Although there is no general consensus about the roles played by the vast majority of tax compliance motives, Casal and Mittone (2016) uphold that literature does agree on the deterrence effect derived from enhanced audit schemes. That is, public economists agree that a higher perceived audit rate, ceteris paribus, would induce taxpayers to be more compliant. Nonetheless, even when the individual decision-

The research presented in this chapter has received funding from the ITN ExSIDE European Union's Horizon 2020 research and innovation programme under the Marie Skłodowska-Curie grant agreement No 721846 . 
making process of tax compliance is a well-studied subject, the strategies from the tax authority's point of view have been typically overlooked.

This paper offers a potential contribution to the fields of public economics and game theory by presenting an optimal strategy from the point of view of the tax authority, who intends to hamper income under-reporting $^{1}$. For a given fixed budget (number) of audits, the tax authority seeks to find the optimal allocation of them in a networked society where taxpayers undergo social interactions at every period. The optimal solution consists on emitting a credible threat-to-audit message which ensures taxpayer heterogeneity with respect to productivity. Immediately afterwards, the tax authority strategically targets taxpayers in function of their individual productivity and their position inside the network. Following, the tax authority audits a key group of taxpayers which, by being targeted, triggers a series of spillover effects across the network. This chain reaction eventually leads to the maximization of the global (mean) subjective audit rate among all taxpayers. Additionally, the unique steady state Nash Equilibrium of the mean subjective audit probability is mathematically characterized. Acknowledging that this is not the first game-theoretic audit policy which has been recommended, to the best of my knowledge, it is the first one to be robust against expected and non-expected utility theories, taxpayer heterogeneity and invariant to any individual payoff or utility function. In such a manner, the network-based approach studied in this paper gives a novel solution to an old problem, while taking into consideration the most recent insights from experimental and behavioral economics in a game-theoretic framework.

The paper is organized as follows. Section 2 offers a comprehensive literature review on tax-evasion modeling, computational techniques to study taxpayer behavior, major findings from field and laboratory experiments regarding individual tax compliance, and recaps some fundamental insights from game theory and network theory applied to public economics. Section 3 presents a game-theoretic approach to tax compliance and studies the optimal strategy from the tax authority's point of view, which is invariant to the decision-making process of the individual taxpayers. Moreover, Section 4 offers an extensive analysis of the optimal enforcement scheme and examines its performance under a variety of settings and model extensions. Finally, Section 5 summarizes the main findings of this paper, discusses the policy implications of the proposed audit strategy, and enumerates the potential limitations and further research ideas germane to this study.

\section{Literature review}

The formal study of tax evasion was pioneered by the work of Allingham and Sandmo (1972), Srinivasan (1973), and Yitzhaki (1974). Their seminal contributions adapted the ideas of Becker (1968) about the economics of crime in a fiscal framework, which served as a cornerstone for the quantitative modeling of tax compliance. Notwithstanding, these influential models were not able to fully replicate taxpayer decision-making. In particular, the levels of tax evasion were systemically overestimated by the seminal models. Thereafter, the expected utility theory was challenged in laboratory experiments designed by Alm, Mcclelland, and Schulze (1992) and Alm, Jackson, and McKee (1992). The authors found that individual taxpayers exhibit considerable heterogeneity in their behavior and seldom respond as the expected utility theory would hypothesize. Consequently, different extensions have been proposed to address this shortcoming ${ }^{2}$. Myles and Naylor (1996) called for the need to consider social norms and conformity, while Andreoni, Feinstein, and Erard (1998) argued in favor of incorporating social interactions to model taxpayer behavior more accurately. Likewise, Yaniv (1999) and Bernasconi and Zanardi (2004) found that prospect theory was able to attain results more in line with empirical evidence.

Computational systems brought a novel technique to model individual decision-making for tax compliance. Mittone and Patelli (2000), Davis, Hecht, and Perkins (2003), Bloomquist (2004), Mittone (2006) and Korobow, Johnson, and Axtell (2007) innovated the research on tax evasion by designing the first agent-based models (ABM's) to simulate taxpayers, social interactions, psychological costs of cheating, social norms, a tax authority and different enforcement settings. Computational techniques and behavioral insights from the social sciences became an integral part of tax research after the seminal paper by

\footnotetext{
${ }^{1} \mathrm{~A}$ working assumption in this paper is that third-party reporting is not available. For scenarios where third-party reporting exists, the results derived in this paper would be applicable without any loss of generality to the self-employed and self-reporting taxpayers.

${ }^{2}$ For a detailed survey of proposed theoretical models, potential utility functions, diverse parameters and specific characterizations of tax compliance models, refer to the survey by Hashimzade, Myles, and Tran-Nam (2013).
} 
Kirchler et al. (2008) introduced the 'slippery slope' framework. The authors combined behavioral and economic motives for tax evasion and distinguished between voluntary and enforced compliance. Hokamp and Pickhardt (2010) developed an agent-based model which took into account psychological reasons, social influence among individuals and granted taxpayers an exponential utility function, which yielded more reasonable outcomes. Additionally, Bloomquist (2011) calibrated the first ABM with real tax data from the Internal Revenue Service department. Furthermore, Prinz, Muehlbacher, and Kirchler (2014) and Pellizzari and Rizzi (2014) provided the first attempts to formalize the 'slippery slope' framework, including taxpayer heterogeneity and considering a wide range of societal parameters.

Andrei, Comer, and Koehler (2014) markedly improved tax evasion simulations by noticing that the underlying structures of taxpayer networks play a significant role in the dynamics of tax compliance. What is more, the authors highlighted a potential role of centrality measures to model aggregate tax compliance. Phillips (2014) argued that audit and penalty rates are not the only policy instruments employable to curb tax evasion, but also game-theoretic insights and representations may contribute to a more efficient solution. Subsequently, Hashimzade, Myles, Page, and Rablen (2014, 2015) and Calimani and Pellizzari (2014) analyzed the emergence of group beliefs, taxpayer behavior and compliance decisions made under uncertainty in an agent-based framework where the transmission of information flowed through peer-to-peer interactions in a social network. Furthermore, Hashimzade, Myles, and Rablen (2016) employed predictive tools to design more sophisticated audit strategies, significantly improving compliance compared to random audits. On top of that, social network models have also been adapted to study criminal activity in diverse economic backgrounds, for example, Patacchini and Zenou (2012), Drezewski, Sepielak, and Filipkowski (2015) and Colladon and Remondi (2017) studied the opportunities for social network analysis to prevent organized crime; such as gang delinquency and money laundering.

In parallel to agent-based models, field experiments and tax surveys have proven to be advantageous methods to further investigate taxpayer behavior. On the one hand, the aftermath of peer-to-peer communication has been thoroughly investigated. Ostrom (2000) asseverated that social norms in games are more effective when players are able to communicate among themselves. Stalans, Kinsey, and Smith (2006) reported that taxpayers with higher opportunities to evade taxes communicate about tax matters more often than their counterparts. Ashby, Webley, and Haslam (2009) suggested that people from the same profession are more likely to interact and exchange information on a frequent basis. Alm, Jackson, and McKee (2009) found that peer-to-peer communication about audits influences taxpayer behavior, and that the effect of audits is not limited to those actually audited. Galbiati and Zanella (2012) explored the entire collection of tax audits performed on self-employed workers in Italy for 1987 and found conclusive evidence of endogenous social effects on tax evasion among taxpayers. However, Onu and Oats (2015) remarked that there is still much to be discovered about the frequency and nature of social interactions among taxpayers. On the other hand, the tax authority may also spark a positive reaction among taxpayers by interacting with them. Field experiments have confirmed the capability of threat-to-audit letters as a tool to persuade tax compliance (Slemrod, Blumenthal, and Christian (2001); Kleven, Knudsen, Kreiner, Pedersen, and Saez (2011); Pomeranz (2015)). Notwithstanding, Scartascini and Castro (2015) noted that sending such threatening messages may backfire in the longer run if no additional and corresponding measures are introduced. Moreover, a study by Whillans, Wispinski, and Dunn (2016) found that tax authorities may impact taxpayers' attitudes and incentive them to comply by framing the idea of wealth as a responsibility by means of simple messages.

More recently, social norms and peer-effects have become a fundamental aspect of tax-compliance modeling. Kogler, Muehlbacher, and Kirchler (2015) suggested that perceived social norms are related to both voluntary and enforced compliance. Alm, Bloomquist, and McKee (2017) found that individuals incorporate the behavior of their 'neighbors' when they decide how much income to disclose and how much taxes to pay. That is, taxpayers take into account the actions of their peers, from whom they receive information or with whom they may interact. Extending the notion of peer-effects, Garz and Pagels (2018) linked how a pronounced media coverage of celebrities being trialed in Germany for fiscal misconduct provoked an augmented number of self-denunciations and raised the participation of German tax evaders in tax-amnesty programs. Furthermore, Gächter and Renner (2018) studied the emergence of group beliefs and pro-social behavior in public goods games with leaders and followers. Although 'highly visible' taxpayers could affect the initial beliefs of other individuals, the most substantial component of individual attitudes came from the average past behavior of other players. Following, the dynamics of 
taxpayer compliance are strongly path-dependent and, once a norm or equilibrium is reached, leaders seldom have the power to re-establish or augment the aggregate compliance level. On top of that, Salmon and Shniderman (2019) claimed that if changes to the enforcement regime are presented in an ambiguous manner, their effect would be negligible. Consequently, instead of vaguely announcing that 'more audits will take place', the tax authority should specify how the number of tax audits will be increased, or announce which people will be the specific target of the reinforced scrutiny. Vardavas et al. (2019) found evasion rates to be proportional to the perceived evasion rate in the population. That is, individuals are less prone to comply whenever they perceive that their peers are cheating with their corresponding tax obligations.

Boning, Guyton, Hodge, Slemrod, and Troiano (2018) and Lopez-Luzuriaga and Scartascini (2019) remarked that threat-to-audit messages not only have direct effects on their targets, but they also spread throughout the taxpayer network. Mentioned influence is commonly known as indirect or 'spillover' effects, which should always be taken into account by the tax authority and policymakers. Riedel, Strohmaier, and Lediga (2019) studied data on business taxes from South Africa and found that audits significantly incremented tax disclosures of non-audited firms. Moreover, these spillover effects of audits diminished with geographical distance and had a short-term effect along time. Drago, Mengel, and Traxler (2020) designed a field experiment targeting potential evaders of TV license fees in Austrian households. The authors found significant spillover effects of compliance behavior, where untreated households switched from evasive to compliant attitudes in response of having their neighbors targeted by the examiners. Aforesaid spillover effects where positively correlated to geographical proximity and to the centrality of the targeted households. Ortega and Scartascini (2020) advocated that the mechanisms through which policies are informed to the public play a leading role in the effectiveness of an intervention. The authors emphasized that the occurrence of a physical visit by an auditor is more effective than an e-mail warning; and both are more efficient than a simple threat-to-audit letter.

Contemporary literature calls for tax authorities to invest in 'big data' tools which would enable policy makers to build taxpayer social networks. Didimo, Grilli, Liotta, Montecchiani, and Pagliuca (2019) and Didimo et al. (2020) found decisive support for analyzing taxpayer social networks to discover tax evasion. Further, Gamannossi degl'Innocenti and Rablen (2020) designed an optimal audit policy aligned with the Ballester, Calvó-Armengol, and Zenou (2006) local-aggregate game, where agents take into account the absolute actions of their peers. Specifically, the authors derived a unique Nash Equilibrium of optimal tax evasion in terms of a Bonacich (Bonacich (1987)) centrality measure; in their context, more central agents tended to evade more. Moreover, their research demonstrated how higher investments in data-oriented tools would allow tax authorities to optimally select the individuals which ought to be audited. On the other hand, Fortin, Lacroix, and Villeval (2007), Blume, Brock, Durlauf, and Jayaraman (2015), Kline and Tamer (2019), Garcia Alvarado (2019) and Ushchev and Zenou (2020) explored the applications of local-average games, where agents take into account the average actions of their neighbors whenever deriving their own optimal action to exert. In particular, Ushchev and Zenou (2020) developed a microfounded model where individuals have a taste for conformity with the social norm and concluded that using common centrality measures to target taxpayers may not necessarily be efficient. Therefore, the authors warn that optimal policies may differ whether the social planner believes agents play a localaggregate game as in Ballester et al. (2006) and Gamannossi degl'Innocenti and Rablen (2020) or a local-average game as Ushchev and Zenou (2020).

\section{Game-theoretic approach to tax compliance}

The current section details a game-theoretic mechanism where $n>1$ individuals face a corresponding tax authority. Taxpayers attempt to maximize their expected utility by choosing the optimal level of income to declare. Meanwhile, the tax authority is concerned with maximizing the aggregate fiscal revenues collected from individual tax payments. In order to do so, the explicit objective of the tax authority is to maximize the global subjective (perceived) audit rate across the entire taxpayer network.

The game works as follows. In Step 1 the initial state of the agents (taxpayers) is delimited by endowing each individual with a set of parameters. At the beginning of Step 2 the tax authority sends a message to all taxpayers aiming to incentive positive taxpayer behavior and persuade individuals to disclose their income. Once the players have been parameterized and the message has been received, Step 3 consists in creating links between players to create a connected network. We say a network is connected 
if there exists at least one path between any two arbitrarily chosen nodes. Moreover, we say two agents are 'neighbors' if they share a direct link between each other. Step 4 pertains to agent interaction and social influence in the sense of Hokamp and Pickhardt (2010) and Andrei et al. (2014). Individuals 'talk to' their neighbors with whom they share a direct link and exchange information which helps them to update their subjective audit rate. During Step 5, individuals maximize their expected utility by choosing their optimal declared income. In Step 6 the tax authority, or social planner, applies its optimal audit strategy intending to maximize the global subjective audit rate; which we assume indirectly maximizes the aggregate level of income declarations and fiscal revenues. Afterwards, the game loops back to Step 4, where individuals share information once more and repeat the process indefinitely. The outline of the game's dynamics is depicted in Table 1.

Table 1: Outline of the dynamic game on tax evasion

\begin{tabular}{|l|l|}
\hline \hline Step & Description \\
\hline Step 1 & Agents (taxpayers) are parameterized. \\
Step 2 & The tax authority emits a threat-to-audit message. \\
Step 3 & The social network is built. \\
Step 4 & Agents hold social interactions and share information. \\
Step 5 & Agents choose their optimal declared income. \\
Step 6 & The tax authority applies its optimal audit strategy. \\
Loop & Go back to Step 4. \\
\hline \hline
\end{tabular}

\section{Step 1: Agent parameters}

In the first step all taxpayers are endowed with an initial set of parameters as specified in Table 2 . The gross income $(I)$ is exogenous and individual-specific. Tax rates $(\tau)$, penalty rates $(\phi)$, true audit rates $(p)$, number of taxpayers $(n)$, fiscal memory length $(m)$, a weighting parameter $(\omega)$ and a taste for conformity $(\theta)$ are exogenous and societal, i.e. they are identical for all agents. Fiscal memory refers to the number of time periods which an agent can recall into the past. The parameter $(\omega)$ refers to the weight that agents give to new information received from other taxpayers. The taste for conformity measures the preference of an individual to follow the social norm. Subjective audit rates $(\hat{p})$ are endogenously computed and may vary among individuals. The declared income $(d)$ is derived endogenously by each individual. Finally, the global subjective audit rate $(q)$ is the mean value of the subjective audit rates among all taxpayers $i \in\{1,2, \ldots, n\}$ in the network.

Table 2: Nature and type of employed parameters

\begin{tabular}{|l|cc|cc|}
\hline \hline Parameter & Exogenous & Endogenous & Societal & Individual \\
\hline$I:$ Earned income & $\mathrm{X}$ & & & $\mathrm{X}$ \\
$\tau:$ Tax rate & $\mathrm{X}$ & & $\mathrm{X}$ & \\
$\phi:$ Penalty rate & $\mathrm{X}$ & & $\mathrm{X}$ & \\
$m:$ Fiscal memory length & $\mathrm{X}$ & & $\mathrm{X}$ & \\
$n:$ Number of taxpayers & $\mathrm{X}$ & & $\mathrm{X}$ & \\
$\omega:$ Weighting parameter & $\mathrm{X}$ & & $\mathrm{X}$ & \\
$\theta:$ Taste for conformity & $\mathrm{X}$ & & $\mathrm{X}$ & \\
$p:$ True audit rate & $\mathrm{X}$ & & $\mathrm{X}$ & \\
$\hat{p}:$ Subjective audit rate & & $\mathrm{X}$ & & $\mathrm{X}$ \\
$d:$ Declared income & & $\mathrm{X}$ & & $\mathrm{X}$ \\
$q:$ Global subjective audit rate & \multicolumn{3}{|c|}{} \\
\hline \hline
\end{tabular}

Formally, the value of $q \in[0,1]$ is computed as: $q=\frac{1}{n} \mathbf{e} \hat{\mathbf{p}}$, where $\mathbf{e}:=(1, \ldots, 1) \in \mathbb{R}^{n}$ is a row-vector of ones with dimension $n$, and $\hat{\mathbf{p}}:=\left(\hat{p}_{1}, \hat{p}_{2}, \ldots, \hat{p}_{n}\right)^{T}$ is the vector of subjective audit rates of all taxpayers in the network, with $\hat{p}_{i} \in[0,1]$ for all $i \in\{1,2, \ldots, n\}$. From a game-theoretic point of view, the objective of the tax authority in this paper is to maximize the global (mean) subjective audit rate $(q)$. 


\section{Step 2: Threat-to-audit message}

The efficiency of threat-to-audit messages has been proven in diverse environments (Slemrod et al. (2001); Alm et al. (2009); Kleven et al. (2011); Pomeranz (2015); Boning et al. (2018); Lopez-Luzuriaga and Scartascini (2019); Drago et al. (2020)). In particular, Alm et al. (2009) concluded that audit enforcement is an effective tool conditional to the taxpayers being aware of the current audit regime. Specifically, the authors found that the influence of post-audit peer-to-peer communication on taxpayer behavior is dependent on whether taxpayers are informed about the audit rates or not. Consequently, the tax authority should opt for pre-announcing audit rates credibly and by emphasizing the audit frequency in the previous period. Therefore, the tax authority hereby designs a simple message which frames the idea of income as a responsibility, in the spirit of Whillans et al. (2016). Moreover, following the recommendation by Salmon and Shniderman (2019), the announcement may include uncertainty but cannot be ambiguous, that is, the tax authority should clearly announce how the regime will change or which agents will be the specific target of the new enforcement scheme.

The explicit message or announcement may be phrased as:

\section{Tax authority:}

Dear citizen,

A new audit regime is in place.

Last year the societal audit probability was of ' $p$ ' and equal for all taxpayers.

As of now, the probability of being audited will be proportional to the income level of each taxpayer.

Albeit authors sometimes disagree on which is the principal attribute which motivates taxpayers to comply (tax morale, risk aversion, reciprocity, social values, reputation, income, etc.) many of them are non-observable and impractical to be estimated. Therefore, this paper considers income, or observable income $^{3}$, as a principal explanatory variable for tax payments in absolute terms, as reported in Alm, Jackson, and McKee (1992). Following, the assumption behind the framing message is rather logical: individuals with eye-catching incomes might naturally attract the attention of the tax authority, while low-income agents potentially may be less profitable to audit ${ }^{4}$.

Furthermore, the threat-to-audit message received from the tax authority requires agents to compute their heterogeneous subjective audit rate $(\hat{p})$, which is derived endogenously for each individual. We consider agents can perceive their individual income with respect to the societal average income as in Pellizzari and Rizzi (2014). Following, the initial value of the individual-specific subjective audit rate for each agent $i$ is computed as:

$$
\hat{p}_{i, t=0}=p \cdot \frac{I_{i}}{\sum_{j=1}^{n} I_{j}} \cdot n,
$$

where $p$ is the homogeneous true audit rate (prior to the tax authority's message and policy design), $I$ denotes individual income, $n$ is the total number of individuals in the society, and $\hat{p} \in[0,1]$. Furthermore, computing the sum over all $i$ and dividing by $n$ on both sides, it is easy to see that the average initial subjective audit rate is equal to $p$. In other words, the tax authority is not modifying the total number of audits to be enforced, but it simply claims that it is shifting the taxpayers' audit probabilities.

\section{Step 3: Social networks, notation and definitions}

Consider $\mathcal{N}$ a set of $n>1$ agents which coexist in a connected network g. Define $\mathbf{H}=\left[h_{i, j}\right]$ with entries $\{0,1\}$ as the $n \times n$ adjacency matrix of network $\mathrm{g}$, where $h_{i, j}=1$ if and only if there is a direct connection between agents $i$ and $j$, and $h_{i, j}=0$ otherwise. Additionally, the network is undirected, which means that $g_{i, j}=g_{j, i}$. The network does not include any self-loops, therefore $g_{i, i}=0$ for all $i=\{1,2, \ldots, n\}$.

Furthermore, define $\mathbf{G}=\left[g_{i, j}\right]$ with entries $\left[g_{i, j}\right] \in[0,1]$ as the $n \times n$ row-normalized adjacency matrix obtained from diving each entry of matrix $\mathbf{H}$ by the degree of node $i$. Following this definition,

\footnotetext{
${ }^{3}$ Income levels may be estimated to great accuracy by considering individual-specific characteristics, such as: consumption, housing, education, ability-type, etc. Moreover, the working assumption in this paper is not that income is perfectly observable. The working assumption is that the tax authority can rank agents by income-productivity levels.

${ }^{4}$ Theoretically, the outcome from the optimal audit strategy is invariant and independent of which individual-specific characteristic is being targeted by the threat-to-audit message, as long as it is observable (estimable) and comparable.
} 
$\left[g_{i, j}\right]=\left[h_{i, j}\right] / N_{i}$, where the node-degree $N_{i}$ represents the number of direct neighbors (links) held by agent $i$. Implementing this matrix representation, one can interpret the value of $\left[g_{i, j}\right]$ as the influence which agent $j$ exerts on agent $i$.

\section{Social norms}

Define $x_{i} \in \mathbb{R}_{+}$as the outcome corresponding to player $i$ and $\mathbf{x}:=\left(x_{1}, x_{2}, \ldots, x_{n}\right)^{T} \in \mathbb{R}_{+}^{n}$ the vector of outcomes from all players in network $\mathrm{g}$. In the current tax compliance context, $x_{i}$ may be understood as the outcome subjective audit rate of agent $i$. Further, define the individual-specific social norm $\bar{x}_{i}$ as the average outcome exerted by agent $i$ 's neighbors. Following, the social norm per each agent $i$ in network g may be expressed as:

$$
\bar{x}_{i}=\sum_{j=1}^{n} g_{i j} x_{j} .
$$

Hence, an agent's social norm is dependent on the outcomes exerted by its neighbors and also on its position inside network $\mathrm{g}$. In matrix form notation, the social norm may be expressed as:

$$
\overline{\mathbf{x}}=\mathbf{G x} .
$$

\section{Spillover effects}

Whenever considering social networks of tax evasion, policy implementations do not only inflict direct effects on individuals, but also spread out indirectly throughout the network. Such indirect reactions, also known as spillover effects, have been documented among taxpayers by Boning et al. (2018), LopezLuzuriaga and Scartascini (2019), Riedel et al. (2019) and Drago et al. (2020).

For any given $\lambda \in[0,1)$, denote by $\mathbf{M}=\left[m_{i, j}\right]$ a $n \times n$ matrix such that:

$$
\mathbf{M}:=(1-\lambda)(\mathbf{I}-\lambda \mathbf{G})^{-1},
$$

where $\mathbf{I}$ is a $n \times n$ identity matrix. Moreover, $\mathbf{M}$ is well-defined and row-normalized (Ushchev and Zenou (2020)). Ushchev and Zenou (2020) interpreted $\mathbf{M}=\left[m_{i, j}\right]$ as the matrix of marginal effects, where $\left[m_{i, j}\right]$ is proportional to the weighted number of walks from agent $i$ to $j$ and a walk of length $k$ is weighted by $\lambda^{k}$. Gamannossi degl'Innocenti and Rablen (2020) labeled the term $(\mathbf{I}-\lambda \mathbf{G})^{-1}$ as the social comparison multiplier and related it to the Bonacich (Bonacich (1987)) centrality of each player. According to the authors, this social multiplier measures the mechanism through which a player's actions 'feed through' into other players' actions.

\section{Step 4: Social interactions}

At the beginning of each loop, i.e. during the fourth step, taxpayers hold social interactions and share information with their neighbors. This paper assumes social interactions to happen in the sense of Hokamp and Pickhardt (2010) and Andrei et al. (2014). Accordingly, this assumption implies two things. On the one hand, agents voluntarily disclose information with their neighbors. On the other hand, individuals compute and assimilate the average value of the new information received from their neighbors. The latter seems to be reasonable as information circulates locally, and taxpayers are assumed to be boundedrational. Following, individuals are capable of absorbing a simple mean value instead of having to keep track of otherwise long sequences of information provided by their neighbors.

\section{Sharing information about subjective audit rates}

Define $\hat{\mathbf{p}}:=\left(\hat{p}_{1}, \hat{p}_{2}, \ldots, \hat{p}_{n}\right)^{T}$ as the vector of subjective audit rates of all players in network $\mathrm{g}$ at an arbitrary time $t$, where $\hat{p}_{i} \in[0,1]$ for all $i \in\{1,2, \ldots, n\}$. Also, define the individual-specific social norm, $\overline{\hat{p}}_{i}$, as the average subjective audit probability held by an agent's neighbors. Following, the social norm per each agent $i$ in network g may be expressed as:

$$
\overline{\hat{p}}_{i}=\sum_{j=1}^{n} g_{i j} \hat{p}_{j} .
$$


Subsequently, the social norm may be expressed in matrix form notation as:

$$
\overline{\hat{\mathbf{p}}}=\mathbf{G} \hat{\mathbf{p}} .
$$

Without any loss of generality and for any time $t$, agents voluntarily disseminate their subjective audit rates to their neighbors during social interactions. Thereafter, taxpayers discover the social-norm value of the subjective audit probability $\left(\overline{\hat{p}}_{i}\right)$ at any arbitrary time $t$ among their neighbors.

\section{Subjective audit rates}

First, consider a vector $\mathbf{A}_{i}:=\left(A_{i, t-1}, A_{i, t-2}, \ldots, A_{i, t-m}\right)^{T} \in\{0,1\}^{m}$ which records taxpayer $i$ 's personal history of audits, where $A_{i, t-s}=1$, if agent $i$ was audited during the period $(t-s)$, and $A_{i, t-s}=0$, otherwise. The size of vector $\mathbf{A}_{i}$ is equal to $m$, the fiscal memory length, which is exogenous and identical for all agents. Individuals compute their own observed frequency of audits, $f$. That is, for each taxpayer $i$ at time $t$, the empirical (historical) probability of being audited is given by:

$$
f_{i, t}=\frac{1}{m} \sum_{s=1}^{m} A_{i, t-s} .
$$

Once the social interactions in the network have taken place, each taxpayer updates its heterogeneous, subjective audit rate $(\hat{p})$, which is endogenous and individual-specific. Following the threat-to-audit message emitted by the tax authority during Step 2, agents must first perform an intermediate step and compute their income heterogeneity with respect to society. Denote an auxiliary variable $(\alpha)$ determined by an agent's income divided by the average income of all the agents in the network; analogous to the transformation occupied in Equation 1. The value of such individual-specific heterogeneity level $\alpha$ is defined as:

$$
\alpha_{i}=\frac{I_{i}}{\sum_{j=1}^{n} I_{j}} \cdot n .
$$

The interpretation of $\alpha$ would be a taxpayer's exogenous-given income productivity with respect to society. For example, if taxpayer $j$ 's earned income would be twice the average income level, then $a_{j}$ would be 2. Computing the sum over all $i$ and dividing by $n$ on both sides, it is easy to see that the average productivity $(\bar{\alpha})$ is equal to 1 , i.e. the total productivity of the network has not been modified.

Gächter and Renner (2018) emphasized that individual belief dynamics in tax compliance are strongly path-dependent with respect to the average past behavior of other players. Taking this remark into consideration, Equation 9 defines the updating mechanism of the endogenous subjective audit rate similarly to Pellizzari and Rizzi (2014), while further specifying for a social-norm parameter. Along these lines, the post-message heterogeneous subjective audit rate for taxpayer $i$ can be expressed as:

$$
\hat{p}_{i, t+1}=\frac{1-\omega}{2} \hat{p}_{i, t}+\frac{1-\omega}{2} f_{i, t}+\omega\left(\alpha_{i} \overline{\hat{p}}_{i, t}\right),
$$

where $\omega \in(0,1)$ is the weight that taxpayers give to the newly acquired information. Hence, the subjective audit rate for a given agent $i$ at time $t+1$ may be affected by three different channels. First, taxpayer $i$ takes into consideration its prior belief about its own endogenous audit rate $\left(\hat{p}_{i, t}\right)$. Second, the taxpayer weighs its own empirical (observed) audit rate $\left(f_{i, t}\right)$. Third, agent $i$ evaluates the social-norm value of the audit rate in its neighborhood $\left(\overline{\hat{p}}_{i, t}\right)$ and translates the newly acquired information in terms of its own individual productivity level $\left(\alpha_{i}\right)$ by applying the transformation $\alpha_{i} \overline{\hat{p}}_{i, t}$, where $\alpha_{i} \overline{\hat{p}}_{i, t} \leq 1$ for all $i \in\{1,2, \ldots, n\}$. The weights placed on the first two terms of Equation 9 are expressed in terms of $\omega$ for simplicity, given that the results derived in the subsequent steps will depend only on the value of $\omega^{5}$.

Thereafter, the dynamics of $\left(\hat{p}_{i, t+1}\right)$ defined in Equation 9 describe the post-message (heterogeneous) subjective audit rates of the taxpayers. Ultimately, this heterogeneous subjective audit rates are the actual values which taxpayers will employ to compute their optimal strategies in their next step.

\footnotetext{
${ }^{5}$ All the weights in Equation 9 may be different from one another, as long as all three weights add up to one.
} 


\section{Step 5: Taxpayers' optimization problem}

A considerable amount of research has been invested to study the process of self-reported income and tax compliance decision-making. Despite the fact that the first models of tax evasion were based on the expected utility theory, many subsequent theories have challenged the original premise.

On the one hand, the seminal idea of Allingham and Sandmo (1972) and modified by Yitzhaki (1974) modeled tax evasion under an expected utility approach. In the original expected utility models, a rational agent receives an exogenous earned income $(I)$ and optimizes its expected utility of net income after taxes $(\tau)$ and applicable penalties fines $(\phi)$. Following, the fraction of declared income $d \in[0,1]$ is chosen to maximize the following expected utility:

$$
E U=p U(I-\tau d I-\phi \tau[I-d I])+(1-p) U(I-\tau d I)
$$

where the taxpayer faces a (perceived) audit probability, $(p)$, of being audited and a complementary probability $(1-p)$ of not being audited. In the first case, the taxpayer's income after taxes and penalty fines would amount to its earned income, minus the taxes paid on declared income, minus the penalty fines applied on undeclared taxes. In the second case, its net income would amount to its earned income minus the taxes paid on declared income. Formally, the necessary and sufficient condition for evasion to take place, i.e. $d>0$, is:

$$
p<\frac{1}{1+\phi} .
$$

Notwithstanding, this condition is regularly met (Hashimzade et al. (2013)). In this sense, agents should be largely non-compliant. Albeit being a revolutionizing model for public economics, the authors themselves acknowledged that the model considerably overestimated the true tax evasion rates and further research was recommended.

On the other hand, Yaniv (1999) and Bernasconi and Zanardi (2004) proposed non-expected utility theories to attain results which were more consistent with empirical evidence. A commonly accepted representation of non-expected utility theory is given by a value function $V$, defined as:

$$
V=\nu_{1}(p, 1-p) v(I-\tau d I-\phi \tau[I-d I])+\nu_{2}(p, 1-p) v(I-\tau d I),
$$

where $\nu_{1}(p, 1-p)$ and $\nu_{2}(p, 1-p)$ are weighting functions that translate the audit and complement probabilities $(p, 1-p)$ into more general transformations. Further, $v(\cdot)$ is a payoff-function, which allows for more general representations than the standard utility functions ${ }^{6}$. Notwithstanding, the early nonexpected utility models were not able to take into account the effect that other taxpayers may have on one's reference income. From then until now, different theoretical models have been proposed over a wide range of potential utility functions, diverse parameters and novel specifications. An exhaustive survey of tax compliance modeling techniques was gathered by Hashimzade et al. (2013), placing particular interest in models which account for social interaction and non-expected utility theories.

Remark 1. The scope of this paper is to explore the optimal actions from the tax authority's point of view. What is more, the enforcement strategy to be introduced in the following step of the current section is optimal independently of the taxpayer decision-making process. That is, the optimal audit scheme is heterogeneity-proof with respect to taxpayers' potential expected and non-expected utility theories, biases, intrinsic motives and social interaction effects.

Notwithstanding, for the sake of completeness, the taxpayer's value function in the current setting is defined by inserting the endogenous and subjective probability definition from Equation 9 into the generalized model presented in Equation 12, as:

$$
V=\hat{p} v(I-\tau d I-\phi \tau[I-d I])+(1-\hat{p}) v(I-\tau d I) .
$$

\footnotetext{
${ }^{6}$ For example, it is commonly assumed that utility functions are concave, i.e. $U^{\prime}(\cdot)>0$ and $U^{\prime \prime}(\cdot)<0$, which is not a requirement for $v(\cdot)$ payoff functions.
} 
Consequently, the agent's optimization problem reduces to maximizing the value function $V$, which is dependent on the endogenous parameter $\hat{p}$, as:

$$
\max _{\{d\}} V(\hat{p}, d, I, \tau, \phi, \cdot)
$$

where agents optimize only over the fraction of income declared $d$, while $I, \tau, \phi$ and any other given parameters are exogenous to the taxpayer maximization problem.

Although this subsection does not fully address the optimal actions from the taxpayer's point of view, further intuition and several explicit solutions to specific models may be found in the literature mentioned below. Some of the non-expected utility theories employed in tax evasion research are: prospect theory (Kahneman and Tversky (1979); Yaniv (1999)), rank-dependent expected utility theory (Quiggin (1982)), Choquet expected utility theory (Chateauneuf (1994)) and cumulative prospect theory (Bernasconi and Zanardi (2004)). Moreover, different explanations have been offered to justify the adherence of expected and non-expected utility models with available empirical evidence: regret and disappointment (Loomes and Sugden (1987)), uncertainty (Kischka and Puppe (1992)), non-additive probabilities (Chateauneuf (1994)), risk aversion (Bernasconi (1998)), ambiguity (Snow and Warren (2005)), over-weighting the detection probability (Arcand and Rota-Graziosi (2005)) and endogenous reference levels (Rablen (2010)). Furthermore, social interaction models have attempted to categorize diverse communal effects such as: psychic costs of tax evasion (Baldry (1986); Gordon (1989)), perception of fairness (Cowell and Gordon (1988)), social customs (Myles and Naylor (1996)), tax morale (Dell'Anno (2009)), and public goods (Pellizzari and Rizzi (2014)). In addition, to mention a few utility functions which have been tested, one may identify: exponential (Hokamp and Pickhardt (2010)), logarithmic (Hashimzade et al. (2013)), and power-law (Pellizzari and Rizzi (2014)) utility functions.

\section{Step 6: An optimal strategy for the tax authority}

\section{Local-average games}

The crux of the business is defined in the last step of the game, where the tax authority seeks an optimal strategy to curb income under-reporting. The presence of social interactions leads taxpayers to experience peer-effects, as in Alm et al. (2017). The standard model to study peer-effects on individual actions is known as local-average model (also called linear-in-means model). The name derives from the fact that agents observe the average action of their neighbors and assimilate this value to compute their best response. In the generalized version of the local-average game, the individual best response $\left(x_{i g}\right)$ of agent $i$ who lives in group $g$ can be characterized as:

$$
x_{i g}=a_{i g} \beta+b_{g} \gamma+\theta \bar{x}_{i}+\epsilon_{i g},
$$

where $a_{i g}$ are the observable individual-specific characteristics of agent $i, b_{g}$ are the exogenous societallevel characteristics which are common for all individuals in group $g, \theta$ is the social interaction effect which measures an individual's reaction to the average outcome of its neighborhood, $\bar{x}_{i}$ stands for the previously defined social-norm value in the neighborhood of $i$ and $\epsilon_{i g}$ is an error term.

According to Blume et al. (2015) and Kline and Tamer (2019), local-average games as specified in Equation 15 have a corresponding linear-quadratic utility function of the form:

$$
U_{i}\left(x_{i}, \mathbf{x}_{-i}, \mathrm{~g}\right)=\pi_{i} x_{i}-\frac{1}{2} x_{i}^{2}-\frac{\theta}{2}\left(x_{i}-\bar{x}_{i}\right)^{2},
$$

where $x_{i}$ is the action or outcome chosen by agent $i, \mathbf{x}_{-i}$ is the vector of actions or outcomes chosen by all other players, $\mathrm{g}$ is the social network and $\pi_{i}$ is an individual productivity parameter which compels an agent to increase its optimal outcome $\left(x_{i}\right)$ value.

On the grounds that the dynamics of the subjective audit rates $(\hat{p})$, defined in Equation 9 , follow the definition of social interactions in the sense of Hokamp and Pickhardt (2010) and Andrei et al. $(2014)^{7}$,

\footnotetext{
${ }^{7}$ Given that probabilities are averaged and not aggregated, the social influence effects should be modeled as in a localaverage game and not as in an local-aggregate game in the sense of Ballester et al. (2006).
} 
the best-reply function of agent $i$ choosing $\hat{p}_{i g}$ in a local-average game is of the form:

$$
\hat{p}_{i g}=a_{i g} \beta+b_{g} \gamma+\theta \overline{\hat{p}}_{i}+\epsilon_{i g},
$$

where $\overline{\hat{p}}_{i}$ is the previously introduced social-norm value for the subjective audit rate in taxpayer $i$ 's neighborhood, the individual characteristics $\left(a_{i g}\right)$ may include income, age, gender, etc. and the societal attributes $\left(b_{g}\right)$ may comprise the enforcement regime characteristics (true audit rates, penalty fines, tax rates, etc.). Subsequently, the corresponding linear-quadratic utility function for agent $i$ at an arbitrary time $t$ (removing the sub-index $t$ for simplicity) may be defined as:

$$
U_{i}\left(\hat{p}_{i}, \hat{\mathbf{p}}_{-i}, \mathrm{~g}\right)=\pi_{i} \hat{p}_{i}-\frac{1}{2} \hat{p}_{i}^{2}-\frac{\theta}{2}\left(\hat{p}_{i}-\overline{\hat{p}}_{i}\right)^{2} .
$$

The first two terms describe the utility of choosing $\hat{p}_{i}$ as an outcome whenever there are no social interactions. The remnant term $\theta\left(\hat{p}_{i}-\overline{\hat{p}}_{i}\right)^{2} / 2$ measures a taxpayer's utility reduction as a result from failing to conform with others. Ushchev and Zenou (2020) labeled this last term as peer-group pressure. In particular, Galbiati and Zanella (2012) studied real data on self-employed workers in Italy and found robust evidence to support that the social-effect term, $\theta$, is strictly larger than zero among self-reporting taxpayers.

Claim 1. Ex ante, i.e. previous to the threat-to-audit message, individuals are homogeneous with respect to productivity $\left(\pi_{i}\right)$, since there is no individual-specific characteristic which compels agents to assume a larger value of the subjective audit rate $\left(\hat{p}_{i}\right)$. As a matter of fact, if individuals are ex ante homogeneous, that is if $\pi_{i}=\pi_{j}$ for all $\{i, j\} \in\{1,2, \ldots, n\}$, then the Nash Equilibrium outcome levels will be identical for all players, independently of the network structure (Patacchini and Zenou (2012)).

In other words, when productivity is identical for all individuals, the outcome of a local-average game does not depend on the network $g$. Conceptually, there is no reason why individuals should be ex ante heterogeneous, as the true audit rate $(p)$ is set by a societal parameter and identical for all agents. This situation generates a crucial predicament since, in our context, the tax authority relies on agent heterogeneity to successfully design an optimal enforcement scheme. To work out this impasse, redefine the productivity vector $(\boldsymbol{\pi})$ as the income productivity vector $(\boldsymbol{\alpha})$ previously specified in Equation 8 . Define:

$$
\pi:=\alpha
$$

The already communicated threat-to-audit message comes in handy for the tax authority at this point, for agents are heterogeneous with respect to the income productivity vector $(\boldsymbol{\alpha})$. Likewise, for future mathematical convenience, redefine the taste for conformity as:

$$
\lambda:=\frac{\theta}{1+\theta},
$$

where $0 \leq \lambda<1$. Inserting Equation 19 and Equation 20 into Equation 18, the individual utility function may be rewritten as:

$$
U_{i}\left(\hat{p}_{i}, \hat{\mathbf{p}}_{-i}, \mathrm{~g}\right)=\alpha_{i} \hat{p}_{i}-\frac{1}{2} \hat{p}_{i}^{2}-\frac{1}{2}\left(\frac{\lambda}{1-\lambda}\right)\left(\hat{p}_{i}-\overline{\hat{p}}_{i}\right)^{2} .
$$

\section{Nash Equilibrium}

Following, each taxpayer $i$ determines the value of $\hat{p}_{i}$ which maximizes the utility function defined in Equation 21, considering the exogenous vector of outcomes for all other agents $\left(\hat{\mathbf{p}}_{-i}\right)$ and the given network (g) structure. Deriving the First Order Conditions with respect to $\hat{p}_{i}$ one obtains:

$$
\frac{\partial U_{i}\left(\hat{p}_{i}, \hat{\mathbf{p}}_{-i}, \mathbf{g}\right)}{\partial \hat{p}_{i}}=\alpha_{i}-\hat{p}_{i}-\frac{\lambda}{1-\lambda}\left(\hat{p}_{i}-\overline{\hat{p}}_{i}\right)=0 .
$$

Solving for $\hat{p}_{i}$, the best-reply function for each agent $i$ is given by:

$$
\hat{p}_{i}=(1-\lambda) \alpha_{i}+\lambda \overline{\hat{p}}_{i},
$$


also characterized as:

$$
\hat{p}_{i}=(1-\lambda) \alpha_{i}+\lambda \sum_{j=1}^{n} g_{i j} \hat{p}_{j} .
$$

The matrix representation of Equation 24 gives:

$$
\hat{\mathbf{p}}=(1-\lambda) \boldsymbol{\alpha}+\lambda \mathbf{G} \hat{\mathbf{p}} .
$$

Solving for $\hat{\mathbf{p}}_{i}$ the Nash Equilibrium $\left(\hat{\mathbf{p}}^{*}\right)$ is defined by:

$$
\hat{\mathbf{p}}^{*}=(1-\lambda)[\mathbf{I}-\lambda \mathbf{G}]^{-1} \boldsymbol{\alpha} .
$$

Applying the definition of matrix $\mathbf{M}$ from Equation 4, the Nash Equilibrium is characterized by:

$$
\hat{\mathbf{p}}^{*}=\mathbf{M} \boldsymbol{\alpha} .
$$

Ultimately, recurring to Equation 6 the equilibrium social norm $\left(\overline{\hat{\mathbf{p}}}^{*}\right)$ is given by:

$$
\overline{\hat{\mathbf{p}}}^{*}=\mathbf{G M} \boldsymbol{\alpha} .
$$

As anticipated by Claim 1, it is easy to verify how both the Nash Equilibrium $\left(\hat{\mathbf{p}}^{*}\right)$ and the social-norm equilibrium $\left(\overline{\hat{\mathbf{p}}}^{*}\right)$ are expressed in terms of the so-called individual income-productivity vector $(\boldsymbol{\alpha})$ and the network structure. This implies that if all taxpayers would be homogeneous, that is if $\alpha_{i}=\alpha_{j}$ for all $\{i, j\} \in\{1,2, \ldots, n\}$, then the equilibrium outcome levels would be the same for all taxpayers and independent of the network structure; hence making network-based policies inoperative. Ushchev and Zenou (2020) proved that, since $\mathbf{G}$ is a row-normalized adjacency matrix, the Nash Equilibrium exists, is unique and is interior for any $\lambda$ such that: $\frac{\lambda}{1-\lambda}>0$. Moreover, the authors proved that, on average, rational Nash Equilibrium and stochastic decision behavior converge to the exact same outcomes. Consequently, the Nash Equilibrium is not affected whether taxpayers follow heuristic rules or optimize under bounded rationality.

\section{Audit targeting}

The objective of the tax authority is to maximize the global subjective audit rate of the entire taxpayer population (defined as $q$ in Section 3). The global optimum from the tax authority's point of view is its first-best outcome, $\hat{\mathbf{p}}^{o}$. First-best outcomes and restorations in local-average games are thoroughly studied problems. In particular, for any local-average game as the one characterized by Equation 21, the first-best outcomes and restorations are well-defined.

Proposition 1. Given a local-average game characterized by the following individual utility function:

$$
U_{i}\left(\hat{p}_{i}, \hat{\boldsymbol{p}}_{-i}, \mathbf{g}\right)=\alpha_{i} \hat{p}_{i}-\frac{1}{2} \hat{p}_{i}^{2}-\frac{1}{2}\left(\frac{\lambda}{1-\lambda}\right)\left(\hat{p}_{i}-\overline{\hat{p}}_{i}\right)^{2},
$$

for each $i \in\{1,2, \ldots n\}$, the first-best outcome, $\hat{\boldsymbol{p}}^{o}$, is a solution to:

$$
\hat{\boldsymbol{p}}=(1-\lambda) \boldsymbol{\alpha}+\lambda \boldsymbol{G} \hat{\boldsymbol{p}}+\lambda \boldsymbol{G}^{T}(\boldsymbol{I}-\boldsymbol{G}) \hat{\boldsymbol{p}},
$$

whose solution is unique, and it is given by:

$$
\hat{\boldsymbol{p}}^{o}=\left[\boldsymbol{I}+\frac{\lambda}{1-\lambda}(\boldsymbol{I}-\boldsymbol{G})^{T}(\boldsymbol{I}-\boldsymbol{G})\right]^{-1} \boldsymbol{\alpha} .
$$

Proof: Ushchev and Zenou (2020) ${ }^{8}$.

Proposition 1 evidences that the first-best outcomes $\left(\hat{\mathbf{p}}^{\circ}\right)$ are expressed in function of the productivity $(\boldsymbol{\alpha})$, the taste for conformity and the network structure. Notwithstanding, whenever the players in a localaverage game do not reach the first-best equilibrium, the social planner (tax authority) may try to restore it by subsidizing or taxing specific individuals in the network.

\footnotetext{
${ }^{8}$ Evidently, the nomenclature of vectors and matrices in Ushchev and Zenou (2020) has been appropriately adjusted to conform with the nomenclature employed in this paper.
} 
Proposition 2. Continuing from Proposition 1, the first-best outcome $\left(\hat{\boldsymbol{p}}^{\circ}\right)$ is restored whenever the social planner endows individuals with the following subsidy/tax per unit of effort:

$$
\boldsymbol{S}^{o}=\frac{\lambda}{1-\lambda} \boldsymbol{G}^{T}(\boldsymbol{I}-\boldsymbol{G}) \hat{\boldsymbol{p}}^{o},
$$

where the optimal per-effort subsidy for each individual $i$ is:

$$
S_{i}^{o}=\frac{\lambda}{1-\lambda} \sum_{j \neq i} g_{j i}\left(\hat{p}_{j}^{o}-\overline{\hat{p}}_{j}^{o}\right) .
$$

Proof: Ushchev and Zenou (2020).

Evidently, the social planner gives a positive subsidy to agents who under-invest in effort and a negative subsidy (taxes) to those who over-invest. Analogous to the first-best outcome, the optimal subsidy/tax values are in function of the taste for conformity and the network structure. Moreover, given that the optimal subsidy/tax is in function of the first-best outcome, which is itself in function of productivity $(\boldsymbol{\alpha})$, then the optimal subsidy/tax is also in function of productivity. Scrutinizing the individual per-effort subsidy from Proposition 2, the social planner subsidizes (taxes) individuals whose neighbors' outcomes are above (below) their respective social-norm values; i.e. the tax authority should subsidize $(\operatorname{tax})$ agents who exert outcomes below (above) those of their neighbors.

Notwithstanding, the tax authority is unable to tax, i.e. reduce, the subjective audit probability of taxpayers. In fact, the tax authority can only subsidize, i.e. augment, taxpayer perceptions by conducting a series of audits on them. Furthermore, the tax authority is constrained to incur on inadequate subsidies, given that optimal subsidies follow a real-valued function while audits are binary variables. For any taxpayer $i$ at an arbitrary time $t$, we have that $S_{i, t}^{o} \in \mathbb{R}$, but $A_{i, t} \in\{0,1\}$. Not only the plausible subsidy values are limited, but also they are discrete since audits cannot be divided among more than one taxpayer. Although the approach presented in this paper is limited with respect to subsidy flexibility, the results of the optimization problem are analogous from the tax authority's point of view.

Thereafter, if the tax authority decides to attempt to restore the first-best outcome, it must choose how to allocate its limited number of audits among all taxpayers. Namely, the objective of the tax authority at an arbitrary time $t$ is to identify the key set of taxpayers, $\mathcal{M}$, to be audited in order to maximize the global subjective audit probability of the entire set of taxpayers $(\mathcal{N})$ for the next period, with $\mathcal{M} \subset \mathcal{N}$, and constrained by a limited number of audits equal to $\lfloor n p\rfloor$, where $n$ is the number of taxpayers and $p$ is the true audit rate ${ }^{9}$. Mathematically, the tax authority's problem is given by:

$$
\begin{aligned}
\max _{\{\mathcal{M} \subset \mathcal{N}\}} & \frac{1}{n} \sum_{i=1}^{n} \hat{p}_{i, t+1}\left(A_{i, t}, \mathbf{A}_{-i, t}, \cdot\right) \\
\text { s.t. } & A_{i, t}=1 \Longleftrightarrow i \in \mathcal{M}, \\
& A_{i, t}=0 \Longleftrightarrow i \notin \mathcal{M}, \\
& |\mathcal{M}| \leq\lfloor n p\rfloor,
\end{aligned}
$$

where the individual subjective probability for all taxpayers $i \in\{1,2, \ldots n\}$ at time $t+1$ is dependent on whether they have been audited or not $\left(A_{i, t}\right)$, and dependent on who else was audited or not $\left(\mathbf{A}_{-i, t}\right)$.

Applying the results from Proposition 1 and Proposition 2 to Equation 29 the solution for the tax authority's maximization problem is straightforward. First, the tax authority is able to compute the vector of optimal individual subsidies $\left(\boldsymbol{S}^{\boldsymbol{O}}\right)$. Afterwards, the tax authority's optimal enforcement strategy is to audit the $\lfloor n p\rfloor$ taxpayers with the maximal individual subsidy $\left(S_{i}^{o}\right)$ values.

Conclusively, given the presence of social influence and heterogeneous income-productivity levels in the taxpayer network, the tax authority is able to design an optimal enforcement regime adopting the properties of local-average games. It is worth mentioning that the proposed enforcement mechanism is static in nature, i.e. it does not depend on time. Nevertheless, the tax authority could simply revise the network structure and update the income-productivity levels next period in order to find the dynamic (successive) key target group to audit.

\footnotetext{
${ }^{9}$ The floor function $(\lfloor n p\rfloor)$ denotes the greatest integer less than or equal to $n p$.
} 


\section{Policy implementation and robustness analysis}

Computer simulation techniques, such as agent-based models, have been proven to be reliable complements for testing game-theoretic hypothesis. Such techniques encompass four broad components: behavior, occupational variation, geographic characteristics and social influence. Behavior denotes the capability to recreate agents of various types and notorious diversity. Occupational variation differentiates individual income and productivity levels. Geographic characteristics assess the location of an agent inside a network structure. Social influence dynamics keep track of connections, indirect spillover effects and social-norm values. When there are costs of forming a link between two nodes in a network-formation model, individuals try to minimize such connection costs. Although local-average games provide a solid workhorse model to simulate social interactions, Ushchev and Zenou (2020) advocate not to ignore homophily behavior. That is, individuals tend to connect with others who have similar productivity levels, reducing their dis-utility costs of failing to conform with the social norm of their peers. Strictly speaking, individuals want to minimize the difference between their outcomes and those of their neighborhood (social norm). Consequently, this section presents an implementation of the hypothesized optimal audit policy, where agents create links among themselves in a first stage, and where homophily behavior emerges.

\section{Simulating taxpayer behavior}

Once the taxpayers have been parameterized (Step 1) and the tax authority has emitted its threat-toaudit message (Step 2), then the network formation process takes place (Step 3). The goal in Step 3 is to create a network structure which accounts for group cohesiveness (homophily) ${ }^{10}$. Group cohesion may be understood as the action of individuals with common attributes to link together and form a social group, subsequently linking the group to other members of society. In the current paper, cohesiveness is based primarily on wealth. That is, linkage probability between two taxpayers is correlated with the similarity of their income levels.

In such a way, the first step is to give each agent a $(x, y)$ node-position in a Cartesian coordinate system. First, taxpayers sample their income from a uniform distribution $I \sim U(\underline{\mathrm{I}}, \bar{I})$, where $\underline{I}$ is the lowest possible income and $\bar{I}$ the highest one. Following, agents set their $y$-axis coordinate as $y_{i}=\left(I_{i}-\underline{I}\right) / \bar{I}$, hence $y_{i} \sim U(0,1)$. Afterwards, the $x$-axis coordinate is set randomly and accordingly to $x_{i} \sim U(0,1)$. The $x$-axis coordinate accounts for all the non-wealth characteristics of the taxpayer. The second step is to compute all the Euclidean distances between nodes and selecting a threshold such that the total number of links is given by the arbitrarily fixed number of agents $(n)$ and the expected node-degree $(v)$. Following, a link will be formed between two nodes only if their Euclidean distance is smaller than or equal to the aforementioned threshold. Thereafter, the resulting graph includes $n v$ links among $n$ nodes. The third step is to connect each isolated node (if any) to its closest neighbor in the Euclidean sense. Lastly, in case the graph is disconnected (more than one isolated cluster exists) a randomly selected node from the largest cluster will form a link with a randomly chosen agent from an isolated cluster; the process will repeat until no isolated cluster remains. In consequence, after row-normalization, the resulting graph corresponds to the network $g$ and the row-normalized adjacency matrix $\mathbf{G}$.

The intuition behind the cohesive geographical distribution of nodes is as follows. Taxpayers are aligned in function of their income in the $y$-axis and according to all other individual characteristics in the $x$-axis. Hence, agents connect to those who are the most similar to them, i.e. their nearest geographical neighbors. Lastly, the minimal amount of additional links are created in order to secure that there are no isolated nodes and that the network graph is connected. The resulting structure is similar to the preferential-attachment and node-fitness models proposed by Gamannossi degl'Innocenti and Rablen (2020).

Remark 2. A taxpayer positioned in a $(x, y)$ plane will link with its peers located inside a circumference centered at itself and of radius equal to a certain threshold. Another aspect to consider is the impact of asymmetry in the taxpayer's awareness space. That is, an agent may attempt to link exclusively with peers of similar wealth (its vision space would be an horizontal ellipse in the plane) or exclusively with peers which share similar $x$-axis characteristics (its vision space would be a vertical ellipse in the plane).

\footnotetext{
${ }^{10}$ For different types of cohesive and non-cohesive networks employed to model tax evasion refer to Andrei et al. (2014), Garcia Alvarado (2019) and Gamannossi degl'Innocenti and Rablen (2020).
} 
Nonetheless, the outcomes of the audit strategy are invariant of geometrical awareness spaces as long as the expected number of links per node ( $v$ ) remains unaltered.

\section{Diverse network-based audit strategies}

In the following, denote the optimal enforcement regime derived in Section 3 as the Subsidy strategy. A natural question to answer would be to compare the efficiency of the proposed Subsidy strategy against other network-based strategies. This section examines several alternative well-known centrality measures, commonly employed in game theory. Betweenness centrality is related to the connectivity and the level of control a node exerts over the information flow. Closeness centrality considers the shortest paths between nodes and measures how efficiently the information is spread through a network. Degree centrality refers to the number of links or connections that a certain individual holds inside the network. Eigenvector centrality (Eigencentrality) measures a node's importance as a consequence of being linked to other important nodes; sometimes it is associated with the prestige of an individual inside a group. Denote Intercentrality as the network-based strategy proposed by Ballester et al. (2006) for local-aggregate games, where nodes are targeted proportionally to their Bonacich centrality. Finally, a Random strategy is tested, where a group of randomly selected taxpayers is audited.

Consider a benchmark scenario with parameters fixed to $n=1000$ individuals, an expected number of links per agent of $v=8$, a weight parameter for new information of $\omega=0.34$, a taste for conformity of $\theta=1$, i.e. $\lambda=0.50$, and a true audit rate of $p=5 \%$. It should be kept in mind that, since individual true audit rates are dependent on the specific audit scheme, the current section understands $p$ as the 'average' true audit rate within the network. Each audit strategy was tested 100 times, and for 40 fiscal periods as in Andrei et al. (2014). The mean time series of the global subjective audit probability $(q)$ attained by each audit strategy is presented in Figure 1. The proposed Subsidy (S, closed dot) audit scheme realized the highest steady state convergence; followed in order by Degree (D, open dot), Random (R, solid line), Intercentrality (I, triangle), Betweenness (B, plus), Closeness (C, asterisk) and Eigencentrality (E, cross). Not only the proposed Subsidy strategy obtained the best results, but it was one of the only two network-based strategies that surpassed the naive random audit scheme.

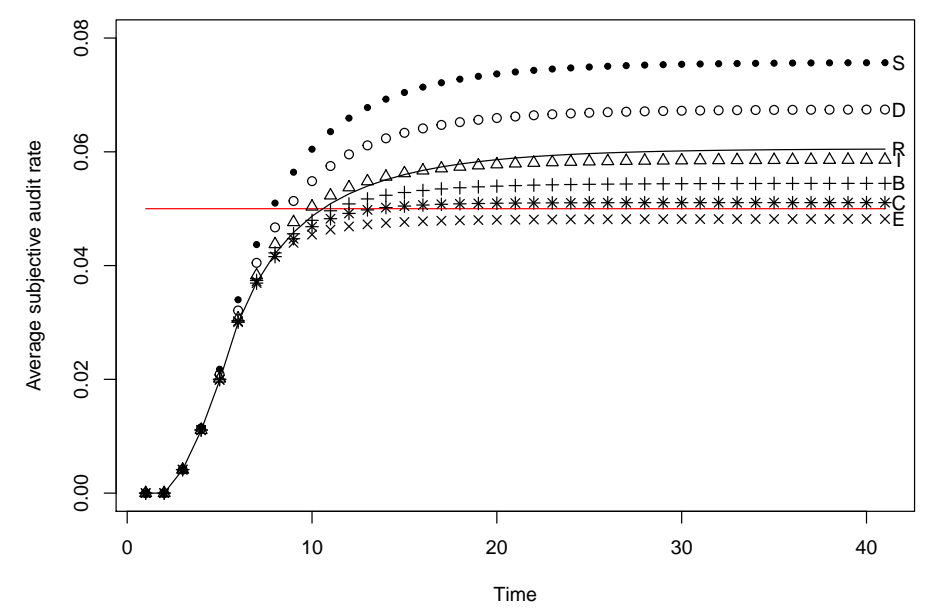

Figure 1: Convergence level of the global subjective audit rate $(q)$ for different audit strategies: Subsidy (S), Degree (D), Random (R), Intercentrality (I), Betweenness (B), Closeness (C) and Eigencentrality (E). The proposed Subsidy strategy secured the highest average convergence level.

The violin plots ${ }^{11}$ in Figure 2 show the distributions of the convergence levels of the global subjective audit rate $(q)$ attained by each audit scheme. Once again, it is clear to see that the proposed audit mechanism consistently achieves the best results. Surprisingly, the Degree-based mechanism also reached

\footnotetext{
${ }^{11}$ Violin plots are similar to box plots, with the addition of displaying the kernel distribution of the sample.
} 
considerably high levels for some runs, albeit inconsistently and with large fluctuations. Nonetheless, even if such less-sophisticated strategy may attain noticeable levels, the variability of results for the Degree scheme is remarkably high. A two-sample t-test confirmed that the Subsidy strategy outperformed the Degree scheme at a $0.001 \%$ confidence level. Notwithstanding, the fact that the Subsidy strategy could be matched under certain circumstances suggests a plausible limitation of enforcing binary audits instead of real-valued subsidies.

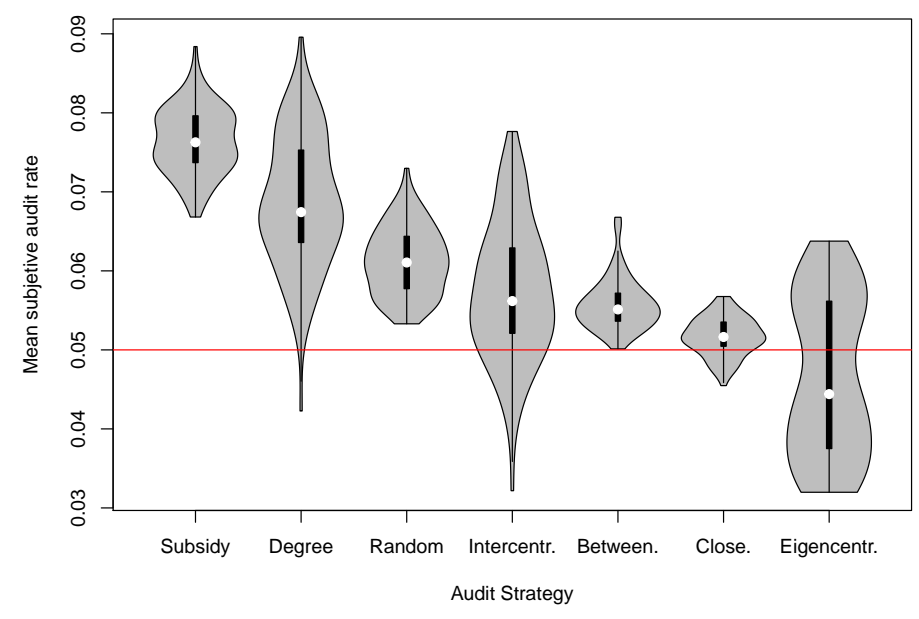

Figure 2: Comparison of the convergence level distributions of the mean (global) subjective audit rate $(q)$ attained by diverse audit schemes. The proposed Subsidy strategy obtained the highest convergence levels. Moreover, the average global subjective audit rate $(\bar{q})$ from the Subsidy strategy outperformed the average global subjective audit rate of the second-best strategy at a $0.001 \%$ confidence level.

\section{Parameter effects and robustness}

The optimal audit strategy derived in Section 3 is robust to individual heterogeneity with respect to potential utility functions and non-expected utility theory decision processes. Notwithstanding, the efficiency of said audit scheme may vary according to the number of individuals $(n)$, the average nodedegree $(v)$, the density of the network $(\delta)$, the (average) true audit rate $(p)$, the attention placed to new information $(\omega)$ and the taste for conformity $(\theta:=\lambda /(1-\lambda))$. In the interest of assessing the role of each parameter, ceteris paribus, a series of simulations were reproduced calibrating each parameter one at a time. Furthermore, the previous benchmark case scenario remains unaltered: $\{n=1000, v=8$, $\omega=0.34, p=5 \%, \lambda=0.50\}$.

The results from six different parameter examinations are presented in Figure 3. Figure 3a shows how the mean (global) subjective audit rate $(q)$ proportionally increases with respect to the expected number of links per node $(v)$; analogous to considering the total number of links. In contrast to this effect, Figure 3b presents how the mean subjective audit probability is inversely proportional to the total number of individuals $(n)$. Also, as noted by Galbiati and Zanella (2012), the dispersion of individual heterogeneity is larger in smaller groups of taxpayers. Intuitively, it would be interesting to test the effect of both parameters simultaneously. Controlling for a constant network density, that is $\delta=v / n$, Figure 3c illustrates how the convergence level of the global subjective audit rate reaches a steady state for $n \geq 1500$. A series of $t$-tests confirmed that, for all values of $n \in\{1500,2000,2500,3000\}$, the null hypothesis (difference in means equals zero) cannot be rejected. Further analysis in Figure $3 \mathrm{~d}$ shows a non-monotonic effect of the taste for conformity on the convergence level of the global subjective audit probability; nonetheless, the strategy achieves positive outcomes for all tested values of $\lambda \in[0.1,0.9]$. This non-monotonic effect follows in line with the results presented by Ushchev and Zenou (2020). 


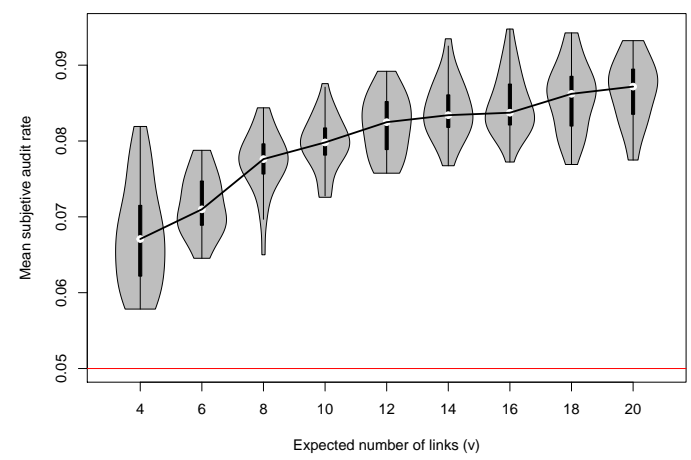

(a) Parameter: Expected node-degree $(v)$

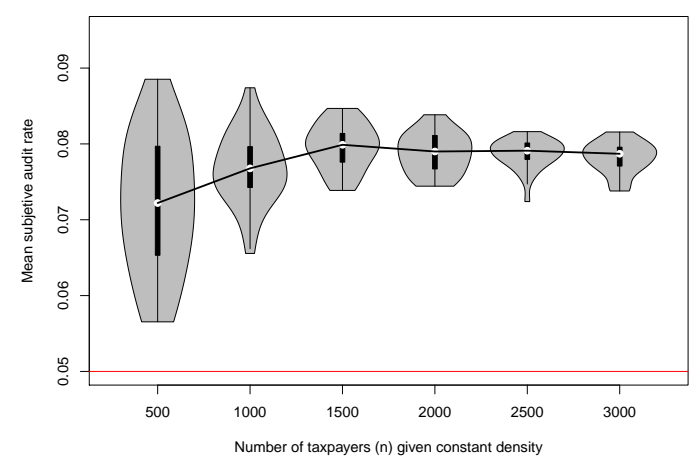

(c) Parameter: Constant density $(\delta)$

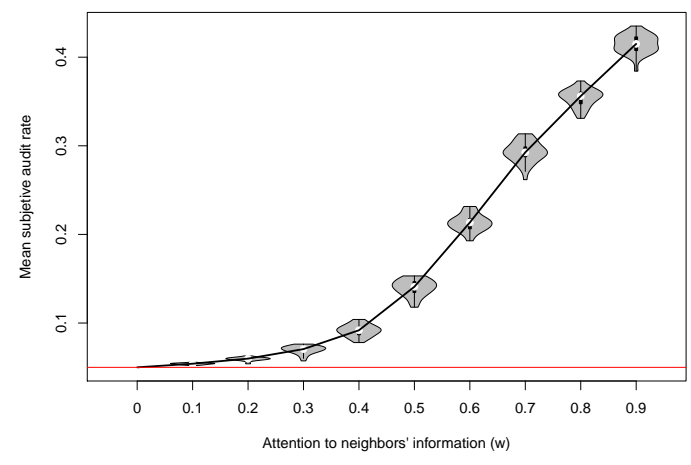

(e) Parameter: Attention to neighbors $(\omega)$

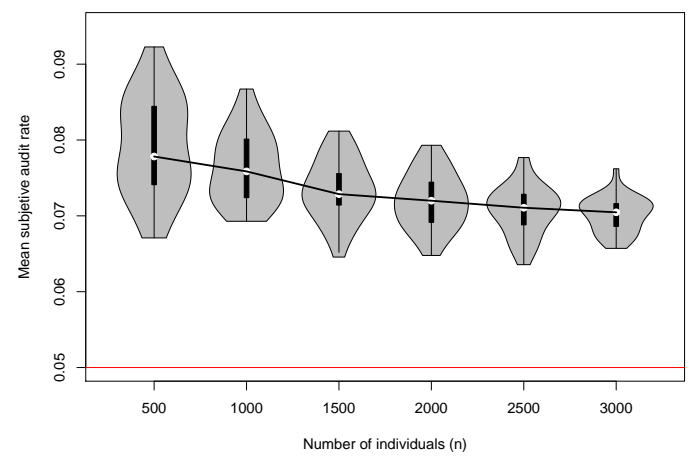

(b) Parameter: Number of individuals $(n)$

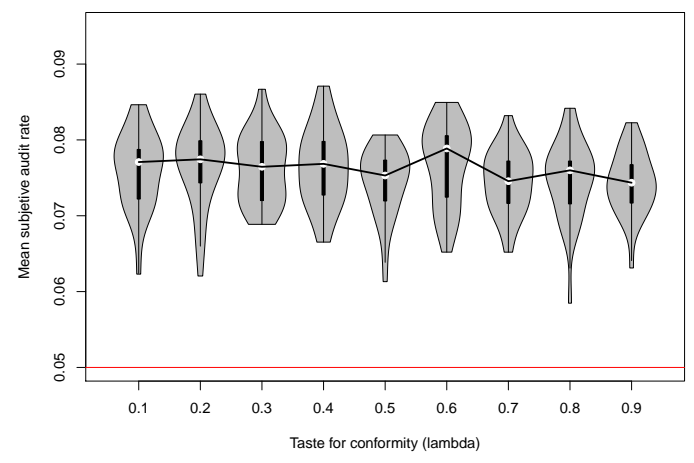

(d) Parameter: Taste for conformity $(\lambda)$

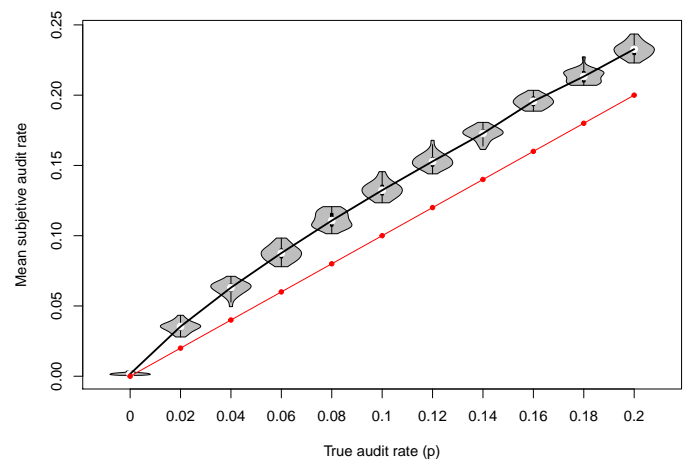

(f) Parameter: 'Average' true audit rate $(p)$

Figure 3: Testing the effect of key parameters on the mean subjective audit rate, ceteris paribus.

Parameters considered: (a) number of individuals $(n)$, (b) expected node-degree $(v)$, (c) constant network density $(\delta),(\mathrm{d})$ taste for conformity $(\lambda),(\mathrm{e})$ attention placed on new information $(\omega)$, and (f) 'average' true audit probability $(p)$.

Another important parameter is the attention level that agents place on the new information acquired from their neighbors $(\omega)$. Figure 3e displays a prominent non-linear relation between the attention level and the steady state of the mean subjective audit probability. On the one hand, if agents place no attention on new information, then the proposed optimal audit strategy would be inefficient. On the other hand, if agents place full attention on new information and disregard their own priors and empirical experience, then the tax authority could reach remarkably high steady-state levels of the mean subjective 
audit rate. At last, Figure $3 f$ compares the attained convergence level of the mean subjective audit probability against the (average) true audit rate $(p)$ for several values of $p \in[0 \%, 20 \%]$. Following, the optimal audit scheme manages to realize a global subjective audit rate $(q)$ significantly larger than the (average) true audit probability $(p)$ for any non-zero audit rate.

\section{Extension: Unsophisticated social interactions}

Onu and Oats (2015) noted that not always taxpayers are willing to share sophisticated information among their peers. Following, the current paper defines a secondary communication channel which limits to simple past observations and abstains from appealing to stronger assumptions. Hence, taxpayers refrain from communicating their expected audit probabilities and only share their empirical frequency of being audited, $f$, during social interactions. The latter is a noisy estimate of the former, yet plausibly it is more realistic to share an observed frequency rather than a computed probability. Consequently, agents learn the social-norm value of the empirical frequency of audits in their neighborhood, i.e. the average $f$-value of their neighbors at time $t$ :

$$
\bar{f}_{i, t}=\sum_{j=1}^{n} g_{i j} f_{j, t} .
$$

A comparison between sharing sophisticated social-norm messages and un-sophisticated ones is represented in Figure 4. Specifically, Figure 4a shows the mean subjective audit rate attained by sharing empirical social-norm messages $(\bar{f})$ and how the fiscal memory length $(m)$ plays a positive role in raising the equilibrium levels. The longer the fiscal memory, the wider the window of opportunity for the tax authority to design an optimal audit scheme. In particular, Figure $4 \mathrm{~b}$ demonstrates how, for a memory length $m \geq 2$, the outcomes of sharing un-sophisticated messages are at least as good as the ones achieved by enabling sophisticated communication among taxpayers.

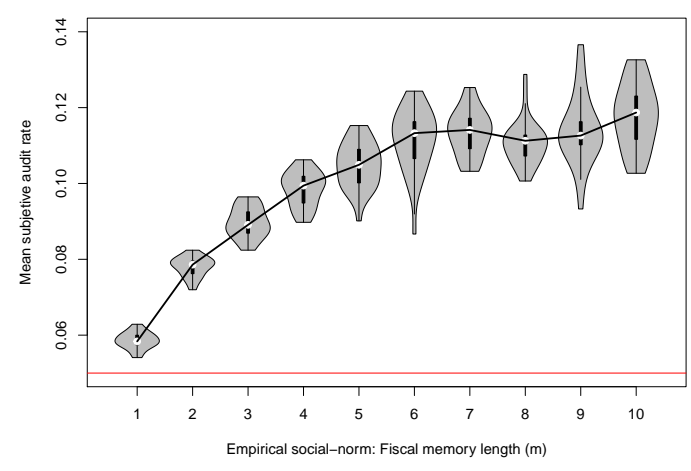

(a) Sharing empirical social-norm messages

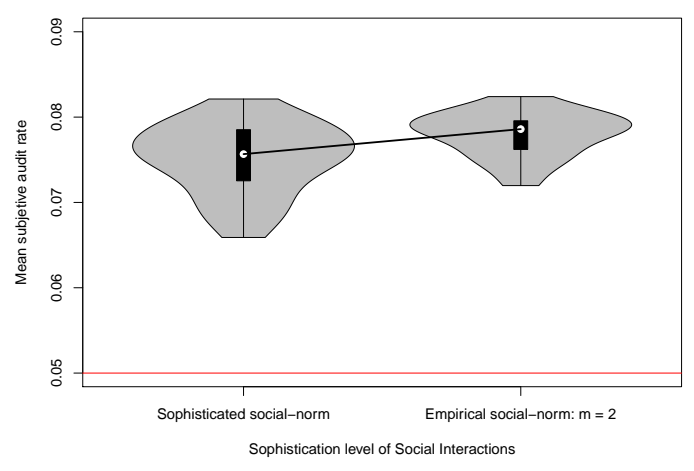

(b) Sophisticated and un-sophisticated messages

Figure 4: For $m \geq 2$ the outcome is at least as good as when sophisticated communication is enabled.

\section{Further extensions and robustness checks}

\section{Directed and undirected taxpayer links}

A recurrent question in network theory is whether the links between agents are directed or undirected. In the former, information flows in a single direction; while in the latter, information flows bilaterally. The previously introduced network $\mathrm{g}$ is undirected and symmetric, which implies that $g_{i, j}=1 \Longleftrightarrow g_{j, i}=1$ and $g_{i, j}=0 \Longleftrightarrow g_{j, i}=0$. Define a directed network $\mathrm{g}^{\prime}, \mathrm{g}^{\prime} \subset \mathrm{g}$, where all taxpayer links are directed and no link is bilateral. Figure 5 illustrates two different scenarios of the directed network: whether the tax authority can distinguish between directed and undirected links, or not. If the social planner can observe the direction of the taxpayer links in network $\mathrm{g}^{\prime}$, Figure 5a shows that the optimal audit strategy would be even more effective than under directed networks, and a two-sample $t$-test confirmed it at a 
0.01\% confidence level. However, if the tax authority would not be able to observe the link direction, it would be forced to solve the optimization problem employing the undirected network g. Figure 5b shows that, although the strategy still attains large convergence levels of the mean subjective audit rate, the outcome of the audit enforcement scheme is weakened. As a remark for both conditions (Figures 5a and $5 \mathrm{~b}$ ), in case some links are allowed to be bilateral, the outcome dispersion would take an intermediate position between the two illustrated distributions, respectively.

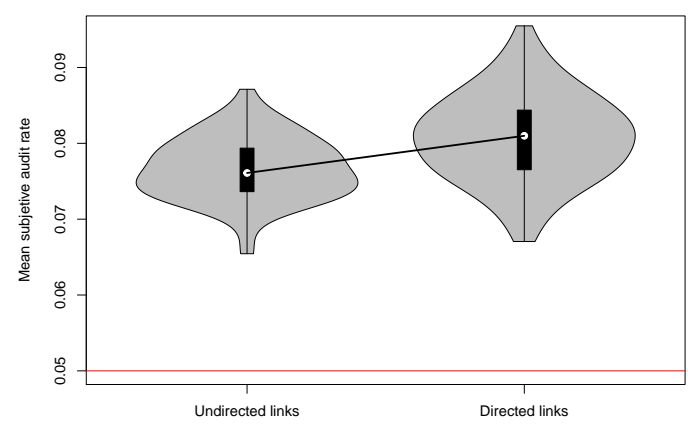

Testing for Observable Directed Networks

(a) The tax authority can distinguish the direction of the taxpayer links.

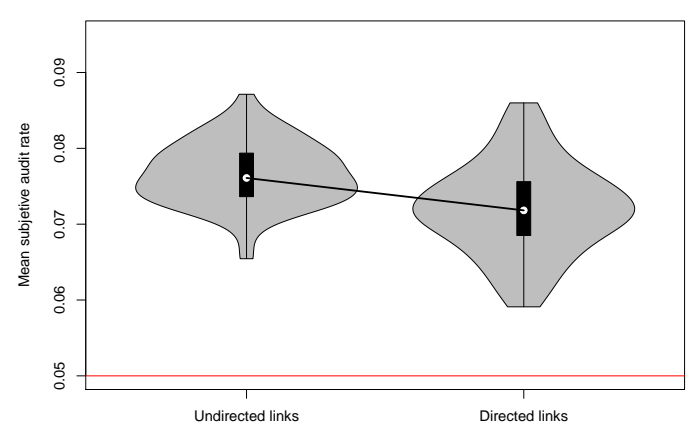

Testing for Unobservable Directed Networks

(b) The tax authority can not distinguish the direction of the links and treats them as undirected.

Figure 5: Comparison between directed and undirected taxpayer links.

\section{Initial subjective audit rate}

Alm et al. (2009) found that the outcome of certain audit enforcement schemes may be dependent on the initial perception of taxpayers regarding audit frequencies. Notwithstanding, computer simulations suggest that the optimal audit strategy derived in this paper is invariant to the taxpayers' initial subjective audit rate distribution at time $t=0$. Denote the initial distribution of subjective audit rates as $\hat{p}_{i, t=0} \sim U(0, \rho)$, for all taxpayers $i \in\{1,2, \ldots, n\}$, where $\rho$ is the maximal possible value for the initial subjective audit rate. Figure 6 a shows that the steady state dispersion is invariant for any value of $\rho \in\{0,0.1,0.2, \ldots, 0.9,1\}$. That is, the initial distribution of taxpayer subjective audit rates $\left(\hat{p}_{i, t=0}\right)$ plays a negligible effect on the convergence level of the mean subjective audit rate. Following, the assumption that taxpayers must know the original (average) true audit rate emitted by the government may be cautiously relaxed.

\section{Non-cohesive networks}

An important remark may be stated regarding the cohesiveness of the taxpayer network structure. Following the precedents by Andrei et al. (2014), Gamannossi degl'Innocenti and Rablen (2020) and Ushchev and Zenou (2020), this paper models social networks of tax evasion considering homophily behavior and cohesive relations among individuals. That is, agents tend to form links with peers who are akin to them and with whom they share similar traits and characteristics. Nonetheless, Figure 6b shows the lack of efficiency attained by the Subisdy audit scheme tested over an Erdos-Renyi random graph, which is wellknown to have no cohesion among nodes. In an Erdos-Renyi random graph model, every pair of nodes has the same probability of forming a link, irrespective of any individual-specific characteristics. The result is a network which has no cohesiveness nor homophily. Consequently, the optimal network-based audit strategy proposed in the current paper would be efficient exclusively for taxpayer networks which retain some cohesive behavior.

\section{Attentiveness to the threat-to-audit message}

The design and implementation of threat-to-audit messages as a tool to curb income under-reporting is a well-studied topic in public economics (Slemrod et al. (2001); Kleven et al. (2011); Pomeranz (2015); 
Whillans et al. (2016); Lopez-Luzuriaga and Scartascini (2019)). For this reason, an extension was modeled to measure the performance of the optimal audit strategy whenever taxpayers ignore the threatto-audit message emitted by the tax authority.

Define $\mu$ as the attentiveness of taxpayers. Following, after the message is sent, a fraction $(1-\mu)$ of agents decide to ignore the message and opt to keep their heterogeneity (income-productivity) levels unchanged. That is, $\alpha_{i}=1$ if $i$ belongs to the fraction of agents who ignored the message ${ }^{12}$. Nonetheless, the tax authority does not know who (if any) decided to ignore the message. Therefore, the targeted taxpayers to be audited are derived as usual. Figure 6c shows a conclusive relationship between the taxpayers' attentiveness and the efficiency of the audit strategy. Ostensibly, as the fraction of agents who listens to the message decreases, the performance of the optimal audit scheme diminishes as well. This result sheds light on the long-standing assumption that threat-to-audit messages should be credible and binding in order to reinforce taxpayer behavior.

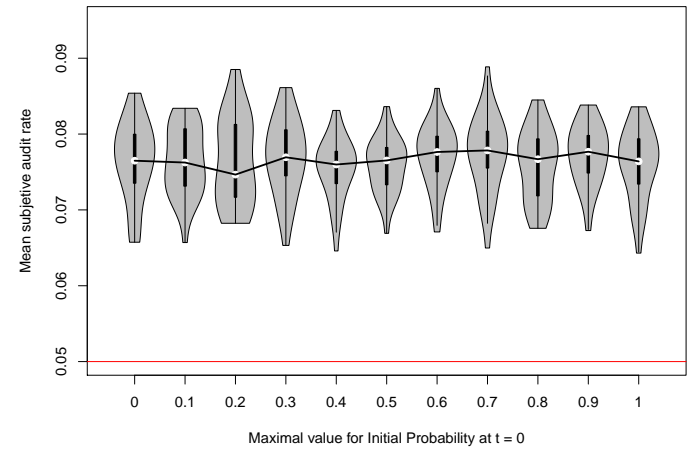

(a) Effect of the initial subjective audit probability

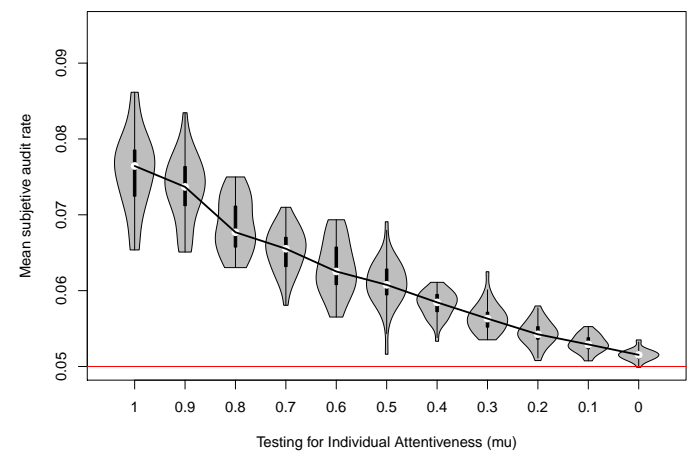

(c) Attention placed to the threat-to-audit message

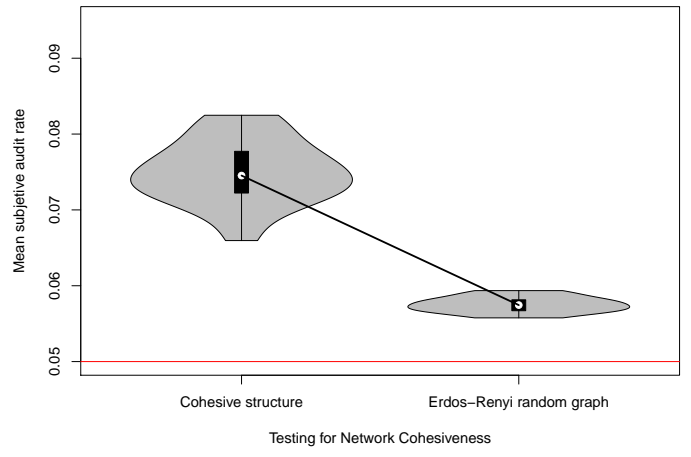

(b) Cohesive and non-cohesive networks

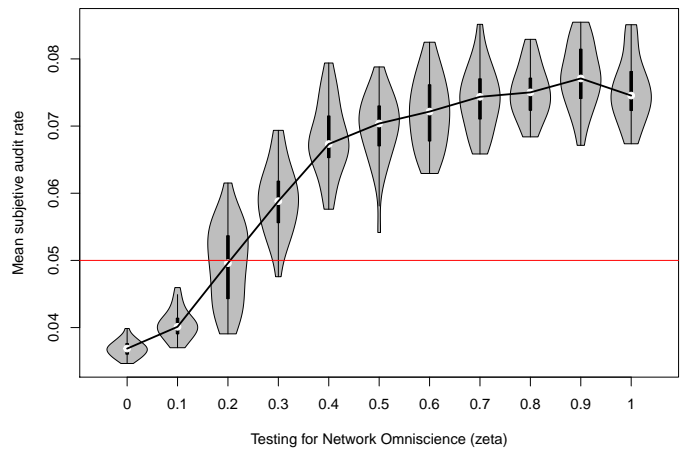

(d) Tax authority's omniscience of the network

Figure 6: Outcomes of the mean (global) subjective audit rate by relaxing several key assumptions: (a) varying initial distributions of the subjective audit rate, (b) the difference between cohesive and noncohesive networks, (c) the level of attention placed on the tax authority's threat-to-audit message, and (d) the fraction of links that the tax authority can unequivocally observe.

\section{Imperfect omniscience by the tax authority}

As considered in Gamannossi degl'Innocenti and Rablen (2020), the last extension appraises the value of information about the true taxpayer social network from the tax authority's point of view. So far, the working assumption on the current paper has been that the tax authority is able to observe all the links

\footnotetext{
${ }^{12}$ Analogously, $1-\mu$ may be considered as the fraction of taxpayers who, by any reason, cannot compute their own heterogeneity level $\alpha_{i}$, and opt to keep their initial value of $\alpha_{i}=1$.
} 
between taxpayers. To relax this assumption, denote as $\zeta$ the fraction of links that the tax authority can unequivocally learn, while it completely ignores the other $(1-\zeta)$ fraction of links. Hence, for an arbitrary $\zeta$, the tax authority computes the optimal vector of subsidies $\left(\mathbf{S}^{\circ}\right)$ using its partially-known network, albeit taxpayers continue to share information across the true complete network. Figure 6d shows a positive and non-linear relation between the tax authority's omniscience level and the efficiency of the proposed audit scheme. Moreover, for a fraction $\zeta>20 \%$ the optimal audit strategy already shows some improvement compared to the true audit rate. Furthermore, if the tax authority unequivocally knows more than $35 \%$ of the true links, i.e. $\zeta>0.35$, the proposed audit scheme outperforms random auditing and most of the alternative network-based policies in the simulations. Consequently, the optimal audit strategy presented in this paper could potentially achieve better-than-most outcomes even with just a share of observable taxpayer links. Finally, according to the simulations, the strategy may accomplish its full potential for any value of $\zeta>0.70$. Hypothetically, if the tax authority could unequivocally observe more than $70 \%$ of the true links, it would be in position to devise and enforce the optimal audit strategy proposed in this paper. Notwithstanding, the costs and plausibility of observing either $35 \%$ or $70 \%$ of the taxpayer links remain open questions.

\section{Conclusions}

\section{Policy implications}

A number of relevant policy implications may be deduced from the research laid out in this paper. First, there is a sizable room for action for threat-to-audit messages and analogous techniques to curb income under-reporting. The present paper studies how the tax authority may influence taxpayer attitudes as in Whillans et al. (2016), while keeping in close attention the correct manner to emit messages proposed by Alm et al. (2009) and Salmon and Shniderman (2019). Moreover, as in Scartascini and Castro (2015), the current paper also shows that the effectiveness of these messages is only consolidated after corresponding measures are introduced (i.e. not lying to the citizens and targeting taxpayers according to the emitted threat-to-audit message). Second, the present study considers income levels as the most reliant observable/estimable individual-specific predictors of tax payments in money terms, as evidenced in Alm, Jackson, and McKee (1992). Nonetheless, there is no need to assume income as the best and only dimension to be treated in the threat-to-audit messages. In fact, the tax authority may aim to target any heterogeneous characteristic which is individual-specific. The tax authority should target the dimension which it believes will encourage taxpayers to increment their income disclosures the most. At last, the current study extends the notions of optimal network-based strategies from Hashimzade et al. (2016) and elucidates a plausible manner in which the tax authority may re-establish the path-dependent aggregate tax-compliance level discussed by Gächter and Renner (2018). Following, the optimal strategy proposed herein targets taxpayers in function of the network structure as in Drago et al. (2020) and Gamannossi degl'Innocenti and Rablen (2020). Consequently, the present paper sheds light to the potential benefits of investing in big data tools and techniques in order to acquire further taxpayer information, which could help the tax authority build accurate taxpayer social networks.

\section{Concluding remarks}

This paper derives an optimal two-step audit strategy, where a threat-to-audit message is emitted by the tax authority in the first step. Said message provides a measurable ex post heterogeneous productivity amid taxpayers. In the second step, the heterogeneity condition allows the tax authority to devise an optimal enforcement regime, derived by means of game-theoretic techniques. Consequently, the proposed optimal audit scheme targets the group of taxpayers who, by being audited, triggers a chain reaction of spillover effects which maximizes the global (mean) subjective audit rate across the entire network. Moreover, a unique Nash Equilibrium is characterized in terms of individual productivity levels and the network structure.

This study presents the first game-theoretic optimal audit strategy which is robust to expected and non-expected utility theories, taxpayer heterogeneity and irrespective of any utility function the individuals may attempt to optimize in their decision-making processes. Furthermore, the tax authority may implement the strategy indifferent to whether taxpayers are fully-rational or not. Additionally, a 
series of computer taxpayer simulations provided supplementary robustness checks for the proposed audit scheme. The optimal strategy is more effective in denser taxpayer networks, invariant to the taste for conformity level, robust to large numbers of taxpayers given a constant network density, and where the outcome efficiency is proportional to the degree of attention that taxpayers place on the new information acquired from their neighbors. Moreover, the audit strategy is robust to un-sophisticated communication during social interactions, and it is applicable for any non-zero (average) true audit rate. Ultimately, the simulation results indicate that, even if only a potentially small fraction of links are observable, the tax authority may still design a better-than-most audit strategy.

Despite the substantial robustness of the game-theoretic model, there are a few inherent limitations which should not go unmentioned. The proposed strategy imposes a degree of cohesiveness among taxpayers and assumes that at least some type of social interaction takes place every period among individuals. Further, the model requires at least a fraction of taxpayers to listen and believe the threatto-audit message, and to take into consideration the new information acquired from their neighbors. Also, taxpayers are expected to be able to get a fair idea of their relative income heterogeneity with respect to their society. Lastly, the tax authority may be unable to accurately estimate income heterogeneity levels, observe links, and it is limited to enforce discrete $\{0,1\}$ audits instead of allocating real-valued optimal interventions. This paper calls for further research in game-theoretic approaches to tax evasion. It is crucial to delve deeper into the process of social interactions among taxpayers and to investigate the possible incurred costs of acquiring additional information in order to build accurate taxpayer social networks.

\section{References}

Allingham, M. G., \& Sandmo, A. (1972). Income tax evasion: A theoretical analysis. Journal of Public Economics, 1(3-4), 323-338.

Alm, J., Bloomquist, K. M., \& McKee, M. (2017). When you know your neighbour pays taxes: Information, peer effects and tax compliance. Fiscal Studies, 38, 587-613.

Alm, J., Jackson, B., \& McKee, M. (1992). Estimating the determinants of taxpayer compliance with experimental data. National Tax Journal, 45(1), 107-14.

Alm, J., Jackson, B. R., \& McKee, M. (2009). Getting the word out: Enforcement information dissemination and compliance behavior. Journal of Public Economics, 93(3-4), 392-402.

Alm, J., Mcclelland, G., \& Schulze, W. (1992). Why do people pay taxes? Journal of Public Economics, 48, 21-38.

Andrei, A. L., Comer, K., \& Koehler, M. (2014). An agent-based model of network effects on tax compliance and evasion. Journal of Economic Psychology, 40(C), 119-133.

Andreoni, J., Feinstein, J., \& Erard, B. (1998). Tax compliance. Journal of Economic Literature, 36, $818-860$.

Arcand, J.-L., \& Rota-Graziosi, G. (2005, 01). Tax compliance and rank dependent expected utility. The Geneva Risk and Insurance Review, 30, 57-69.

Ashby, J., Webley, P., \& Haslam, S. (2009). The role of occupational taxpaying cultures in taxpaying behaviour and attitudes. Journal of Economic Psychology, 30, 216-227.

Baldry, J. C. (1986). Tax evasion is not a gamble: A report on two experiments. Economics Letters, 22(4), 333-335.

Ballester, C., Calvó-Armengol, A., \& Zenou, Y. (2006). Who's who in networks. Wanted: The key player. Econometrica, $74(5), 1403-1417$.

Becker, G. (1968). Crime and punishment: An economic approach. Journal of Political Economy, 76, $169-169$.

Bernasconi, M. (1998). Tax evasion and orders of risk aversion. Journal of Public Economics, 67(1), $123-134$.

Bernasconi, M., \& Zanardi, A. (2004). Tax evasion, tax rates, and reference dependence. FinanzArchiv, $60(3), 422-445$.

Bloomquist, K. (2004). Multi-agent based simulation of the deterrent effects of taxpayer audits. Proceedings. Annual Conference on Taxation and Minutes of the Annual Meeting of the National Tax Association, 97 . 
Bloomquist, K. (2011). Tax compliance as an evolutionary coordination game: An agent-based approach. Public Finance Review, 39(1), 25-49.

Blume, L. E., Brock, W. A., Durlauf, S. N., \& Jayaraman, R. (2015). Linear social interactions models. Journal of Political Economy, 123(2), 444-496.

Bonacich, P. (1987). Power and centrality: A family of measures. American Journal of Sociology, 92, $1170-1182$.

Boning, W. C., Guyton, J., Hodge, R. H., Slemrod, J., \& Troiano, U. (2018). Heard it through the grapevine: Direct and network effects of a tax enforcement field experiment (NBER Working Papers). National Bureau of Economic Research, Inc.

Buehn, A., \& Schneider, F. (2012). Size and development of tax evasion in 38 OECD coutries: What do we (not) know? Journal of Economics and Political Economy, 3.

Calimani, S., \& Pellizzari, P. (2014). Tax enforcement in an agent-based model with endogenous audits (Lecture Notes in Economics and Mathematical Systems: Artificial Economics and Self Organization No. 669). Springer, Cham.

Casal, S., \& Mittone, L. (2016). Social esteem versus social stigma: The role of anonymity in an income reporting game. Journal of Economic Behavior \& Organization, 124(C), 55-66.

Chateauneuf, A. (1994). Modeling attitudes towards uncertainty and risk through the use of Choquet integral. Annals of Operations Research, 52, 1-20.

Colladon, A., \& Remondi, E. (2017). Using social network analysis to prevent money laundering. Expert Systems with Applications, 67, 48-59.

Cowell, F., \& Gordon, J. (1988). Unwillingness to pay: Tax evasion and public good provision. Journal of Public Economics, 36(3), 305-321.

Davis, J., Hecht, G., \& Perkins, J. (2003). Social behaviors, enforcement, and tax compliance dynamics. The Accounting Review, 78, 39-69.

Dell'Anno, R. (2009). Tax evasion, tax morale and policy maker's effectiveness. Journal of Behavioral and Experimental Economics (formerly The Journal of Socio-Economics), 38(6), 988-997.

Didimo, W., Grilli, L., Liotta, G., Menconi, L., Montecchiani, F., \& Pagliuca, D. (2020). Combining network visualization and data mining for tax risk assessment. IEEE Access, 8, 16073-16086.

Didimo, W., Grilli, L., Liotta, G., Montecchiani, F., \& Pagliuca, D. (2019). Visual querying and analysis of temporal fiscal networks. Information Sciences, 505.

Drago, F., Mengel, F., \& Traxler, C. (2020). Compliance behavior in networks: Evidence from a field experiment. American Economic Journal: Applied Economics, 12(2), 96-133.

Drezewski, R., Sepielak, J., \& Filipkowski, W. (2015). The application of social network analysis algorithms in a system supporting money laundering detection. Information Sciences, 295, 18-32.

Fortin, B., Lacroix, G., \& Villeval, M. C. (2007). Tax evasion and social interactions. Journal of Public Economics, 91 (11-12), 2089-2112.

Galbiati, R., \& Zanella, G. (2012). The tax evasion social multiplier: Evidence from Italy. Journal of Public Economics, 96(5), 485-494.

Gamannossi degl'Innocenti, D., \& Rablen, M. D. (2020). Tax evasion on a social network. Journal of Economic Behavior \& Organization, 169(C), 79-91.

Garcia Alvarado, F. (2019). Network-based policies versus tax evasion. In A. S. Chakrabarti, L. Pichl, \& T. Kaizoji (Eds.), Network theory and agent-based modeling in economics and finance (pp. 405-428). Springer Singapore.

Garz, M., \& Pagels, V. (2018). Cautionary tales: Celebrities, the news media, and participation in tax amnesties. Journal of Economic Behavior \& Organization, 155.

Gordon, J. (1989). Individual morality and reputation costs as deterrents to tax evasion. European Economic Review, 33(4), 797-805.

Gächter, S., \& Renner, E. (2018). Leaders as role models and 'belief managers' in social dilemmas. Journal of Economic Behavior 63 Organization, 154.

Hashimzade, N., Myles, G., Page, F., \& Rablen, M. (2015). The use of agent-based modelling to investigate tax compliance. Economics of Governance, 16(2), 143-164.

Hashimzade, N., Myles, G., \& Rablen, M. (2016). Predictive analytics and the targeting of audits. Journal of Economic Behavior and Organization, 124(C), 130-145.

Hashimzade, N., Myles, G., \& Tran-Nam, B. (2013). Applications of behavioural economics to tax evasion. Journal of Economic Surveys, 27. 
Hashimzade, N., Myles, G. D., Page, F., \& Rablen, M. D. (2014). Social networks and occupational choice: The endogenous formation of attitudes and beliefs about tax compliance. Journal of Economic Psychology, 40(C), 134-146.

Hokamp, S., \& Pickhardt, M. (2010). Income tax evasion in a society of heterogeneous agents - Evidence from an agent-based model. International Economic Journal, 24(4), 541-553.

Kahneman, D., \& Tversky, A. (1979). Prospect theory: An analysis of decision under risk. Econometrica, $47(2), 263-91$.

Kirchler, E., Hoelzl, E., \& Wahl, I. (2008). Enforced versus voluntary tax compliance: The "slippery slope" framework. Journal of Economic Psychology, 29(2), 210-225.

Kischka, P., \& Puppe, C. (1992). Decisions under risk and uncertainty: A survey of recent developments. Zeitschrift für Operations Research, 36, 125-147.

Kleven, H. J., Knudsen, M. B., Kreiner, C., Pedersen, S., \& Saez, E. (2011). Unwilling or unable to cheat? Evidence from a tax audit experiment in Denmark. Econometrica, 79(3), 651-692.

Kline, B., \& Tamer, E. (2019). Econometric analysis of models with social interactions. In B. Graham \& A. De Paula (Eds.), The econometric analysis of network data (p. Forthcoming). Elsevier, Amsterdam.

Kogler, C., Muehlbacher, S., \& Kirchler, E. (2015). Testing the "slippery slope framework" among self-employed taxpayers. Economics of Governance, 16, 125-142.

Korobow, A., Johnson, C., \& Axtell, R. (2007). An agent-based model of tax compliance with social networks. National Tax Journal, 60(3), 589-610.

Kukk, M., Paulus, A., \& Staehr, K. (2020). Cheating in Europe: Underreporting of self-employment income in comparative perspective. International Tax and Public Finance, 27(2), 363-390.

Loomes, G., \& Sugden, R. (1987). Testing for regret and disappointment in choice under uncertainty. Economic Journal, 97(388a), 118-129.

Lopez-Luzuriaga, A., \& Scartascini, C. (2019). Compliance spillovers across taxes: The role of penalties and detection. Journal of Economic Behavior 6 Organization, 164(C), 518-534.

Mittone, L. (2006). Dynamic behaviour in tax evasion: An experimental approach. Journal of Behavioral and Experimental Economics (formerly The Journal of Socio-Economics), 35(5), 813-835.

Mittone, L., \& Patelli, P. (2000). Imitative behaviour in tax evasion (Economic simulations in swarm: Agent-based modelling and object oriented programming).

Myles, G., \& Naylor, R. (1996). A model of tax evasion with group conformity and social customs. European Journal of Political Economy, 12(1), 49-66.

Onu, D., \& Oats, L. (2015). "Paying tax is part of life": Social norms and social influence in tax communications. Journal of Economic Behavior $\&$ Organization, 124.

Ortega, D., \& Scartascini, C. (2020). Don't blame the messenger. The delivery method of a message matters. Journal of Economic Behavior \&3 Organization.

Ostrom, E. (2000). Collective action and the evolution of social norms. Journal of Economic Perspectives, $14,137-158$.

Patacchini, E., \& Zenou, Y. (2012). Juvenile delinquency and conformism. Journal of Law, Economics, and Organization, 28(1), 1-31.

Pellizzari, P., \& Rizzi, D. (2014). Citizenship and power in an agent-based model of tax compliance with public expenditure. Journal of Economic Psychology, 40(C), 35-48.

Phillips, M. D. (2014). Deterrence vs. gamesmanship: Taxpayer response to targeted audits and endogenous penalties. Journal of Economic Behavior \& Organization, 100(C), 81-98.

Pomeranz, D. (2015). No taxation without information: Deterrence and self-enforcement in the Value Added Tax. American Economic Review, 105(8), 2539-2569.

Prinz, A., Muehlbacher, S., \& Kirchler, E. (2014). The slippery slope framework on tax compliance: An attempt to formalization. Journal of Economic Psychology, 40(C), 20-34.

Quiggin, J. (1982). A theory of anticipated utility. Journal of Economic Behavior E Organization, 3(4), $323-343$.

Rablen, M. D. (2010). Tax evasion and exchange equity: A reference-dependent approach. Public Finance Review, 38(3), 282-305.

Riedel, N., Strohmaier, K., \& Lediga, C. (2019). Spatial tax enforcement spillovers: Evidence from South Africa (Annual Conference 2019 (Leipzig): 30 Years after the Fall of the Berlin Wall - Democracy and Market Economy). Verein für Socialpolitik / German Economic Association. 
Salmon, T. C., \& Shniderman, A. (2019). Ambiguity in criminal punishment. Journal of Economic Behavior \& Organization, 163(C), 361-376.

Scartascini, C., \& Castro, L. (2015). Tax compliance and enforcement in the pampas evidence from a field experiment. Journal of Economic Behavior \&3 Organization, 116, 65-82.

Slemrod, J., Blumenthal, M., \& Christian, C. (2001). Taxpayer response to an increased probability of audit: Evidence from a controlled experiment in Minnesota. Journal of Public Economics, 79(3), $455-483$.

Snow, A., \& Warren, R. (2005). Ambiguity about audit probability, tax compliance, and taxpayer welfare. Economic Inquiry, 43(4), 865-871.

Srinivasan, T. (1973). Tax evasion: A model. Journal of Public Economics, 2(4), 339-346.

Stalans, L., Kinsey, K., \& Smith, K. (2006). Listening to different voices: Formation of sanction beliefs and taxpaying norms. Journal of Applied Social Psychology, 21, 119-138.

Ushchev, P., \& Zenou, Y. (2020). Social norms in networks. Journal of Economic Theory, 185.

Vardavas, R., Katkar, P., Parker, A. M., Aliyev, G. R., Graf, M., \& Kumar, K. B. (2019). RAND's interdisciplinary behavioral and social science agent-based model of income tax evasion..

Whillans, A. V., Wispinski, N. J., \& Dunn, E. W. (2016). Seeing wealth as a responsibility improves attitudes towards taxation. Journal of Economic Behavior \& Organization, 127(C), 146-154.

Yaniv, G. (1999). Tax compliance and advance tax payments: A prospect theory analysis. National Tax Journal, 52(4), 753-764.

Yitzhaki, S. (1974). Income tax evasion: A theoretical analysis. Journal of Public Economics, 3(2), 201-202. 